\title{
- DOUTORADO -
}

\section{4}

SADOWSKI, Georg Robert

Tectônica da Serra de Cubatão, São Paulo. 27 de dezembro. 159p. Orientador: Yociteru Hasui

Resumo: A Serra de Cubatão é constituída por dois blocos tectô nicos maiores subdivididos pela falha do Cubatão em blo co Juquitiba ao Norte e Litorâneo ao Sul. No bloco Juquitiba dominam migmatitos estromatiticos de paleossoma gnáissico e xistoso envolvendo núcleos ant formais de migmatitos oftalmiticos conformados por do bras de segunda geração. As fases de dobramentos pene trativos são no mínimo três nos estromatitos e chegam a cinco nos núcleos antiformais. Neste bloco, as fases de metamorfismo regional são no mínimo duas, todavia se considerarmos o crescimento de granadas, de feldspatos e a migmatização o número de fases será maior. 0 grau de metamorfismo dominante é do fácies almandina sillima nita anfibolito para as primeiras fases sendo de fácies $x$ isto verde (epidoto, clorita, moscovita) na última.

o bloco Litorâneo é constituído por migmatitos dominan temente oftalmiticos e de paleossoma gnáissico. As fa ses de migmatização são maiores do que as constatadas no bloco Juquitiba como também as fases de dobramento, que no caso seriam no mínimo quatro fases penetrativas. o grau de metamorfismo é elevado, facies anfibolito al to com neossomas desde alcalinos até mais cálcicos. Uma série de zonas de cizalhamento dúctil e falhas corta es te bloco com direção N4O-60E, tais como as falhas de Jú rubatuba, Bertioga e Freires.

No geral a migmatização aumenta para o litoral como tam bém o grau de deformação. Supõe-se daí que a falha dó Cubatão seja uma estrutura de primeira ordem.

Dentro da zona de falha está pinçada uma faixa de metas sedimentos de grau de metamorfismo variando de $x i s t o$ ver de a anfibolito da ordem de $3 \mathrm{~km}$ de espessura e que por vezes é confundida com os filonitos e milonitos associa dos. Componentes de empurrão foram observados na falhá com vergência para NW embora as feições gerais sejam de transcorrência. A falha corta granitos pós-tectônicos como o de Paranapiacaba com idades K-Ar da ordem de 480 m. a.

As fases de atividades ignea são correspondentes a uma atividade básica pré-metamórfica, a uma atividade ignea granitóide sintectônica e para-autoctone com geração de migmatitos concomitâneos, uma fase pós-tectônica gran $\underline{1}$ tica. 
Uma última fase relacionada à abertura do Atlântico é caracterizada por diques de lamprófiros e básicas.

0 trabalho ainda discute a estratigrafia do suposto gru po Assungui e seu embasamento no local.

SANCHEZ, Wladimir

Contribuição à determinação da vazão sólida de arraste em leitos arenosos utilizando técnicas radioisotópicas. 05 de março. 206p. Orientador: Nelson Ellert

Resumo: Estudou-se com auxilio das técnicas radioisotópicas um processo de medida direta da vazão sólida de arraste, em leitos arenosos. Em canal experimental de laborató rio determinaram-se as tensões iniciais de arrastamento para grãos pertencentes a diversos intervalos granulomé tricos, levando-se em conta diferentes valores de vazåo líquida. Realizou-se um estudo comparativo sobre a mo vimentação inicial de grãos de vidro moído e grãos de areia, ambos com mesmo peso especifico e pertencentes ao mesmo intervalo granulométrico. Desenvolveram-se es tudos sobre a determinação da massa mínima de grãos de areia radioativos, destinados a lançamento no escoamen to, levando-se em conta os dois tipos de deteção: está tica e dinâmica. Experiências complementares realizáa das no campo serviram para confirmar as condições tecno lógicas de aplicação do método. Nossa contribuição pes soa?, neste trabalho, refere-se ao tratamento dos sedi mentos antes da irradiação ou marcação (separação granu lométrica e densimétrica para obter-se proporcionalida de entre atividade e massa irradiada) e também ao trata mento dos resultados. As experiências foram realizadas com técnicas e princípios já desenvolvidos e aplicados cuidadosamente.

TORQUATO, Joaquim Raul Ferreira

Geologia do sudoeste de Moçâmedes e suas relações com a evolução tectônica de Angola. 16 de agosto. 243p.

Orientador: Gilberto Amaral

Resumo: 0 autor inicia o presente trabalho localizando e carac terizando a área estudada e fazendo uma retrospectiva histórica da evolução dos conhecimentos sobre a região. No segundo capítulo procura dar uma idéia dos métodos de trabalho e técnicas usadas quer nos trabalhos de cam po, quer ainda nos estudos laboratoriais, especialmente no que se refere às determinações radiométricas.

A geologia regional está descrita no terceiro capítulo. Começa-se com uma breve resenha geomorfológica sobre os principais aspectos da região, descrevendo-se seguida mente as características geológicas de cada uma das uni dades mapeadas. Continua-se, fazendo breves referên 
cias à geologia econômica, hidrologia e vestígios arqueo lógicos encontrados durante o decorrer dos trabalhos. Especial referência é dada à evolução geocronológica com caracterização de cinco eventos tectônicos: Pan-Africa no $(550 \pm 100 \mathrm{m.a.})$, Kibariano (950 $\pm 100 \mathrm{m.a.})$, Muende $(1300 \pm 100)$, Namib $(1675 \pm 72)$ e Eburneano $(2000 \pm 200)$. Os dois primeiros (Pan-Africano e Kibariano) e o último (Eburneano) já eram descritos em várias regiões da Áfrí ca, os eventos Muende e Namib são descritos pela prime $\underline{i}$ ra vez. São igualmente descritas algumas manifestações anorogênicas que afetaram a porção angolana da Platafor ma Africana.

o quarto capitulo é dedicado à interpretação da evolú ção geológica de Angola. Definem-se algumas unidades estruturais que condicionaram a sedimentação fanerozói ca (Aulacógeno de Cassanje, Arco do Zaire, Arco de Moçâ medes e Horst do Cuanza) e procura-se interpretar resu midamente a sua história Pré-Cambriana. Como apêndice, procuramos, através dos dados disponíveis, elaborar, ao que sabemos, a primeira aproximação de uma carta tectô nica de Angola.

Termina-se este trabalho apresentando no quinto capítu lo uma tentativa de correlação geológica Pré-Cambriana entre a região costeira da América do Sul e Africa. Pró põe-se a existência de um geotumor que ligaria os arcos de Moçâmedes em África e Ponta Grossa no Brasil e con clui-se pela existência de uma geossutura de proporções gigantescas que atravessaria toda a África, ligando as cidades de Moçâmedes e Djibouti.

1975

BRITO NEVES, Benjamim Bley de

D-004

Regionalização geotectônica do pré-cambriano nordestino. 29 de se tembro. 198p.

Orientador: Setembrino Petri

Resumo: Este trabalho consiste na primeira tentativa de zonea mento geotectônico do Nordeste Oriental do Brasil, na es cala $1: 2.500 .000$, fundamentada em mapas geológicos pré existentes, de diversas fontes e de escalas de reconhẹ cimento, notadamente 1:250.000 e inferiores.

E proposto um esquema baseado na concepção de "região geossinclinal em mosaico", de natureza ensiálica, e ins talado entre núcleos cratônicos do São Francisco e São Luiz ao final do Proterozóico. Nesta região foram iden tificados e nomeados experimentalmente seus diferentes compartimentos geotectônicos, a saber, maciços media nos, zonas geoanticlinais (altos tectônicos), e as fai xas de dobramentos principais, dos tipos marginal e in 
.4 .

\begin{abstract}
teriores. 0 papel das falhas profundas policíclicas e das rochas graniticas do Ciclo Brasiliano é enfatizado no arranjo complexo dos elementos desta ampla região. 0 acervo de dados geocronológicos preexistentes foi re examinado e grande empenho foi dado na obtenção de no vos dados, pelos métodos $K-A r$ e Rb-Sr, principalmenté nos altos tectônicos. Estes dados foram decisivos para identificar a presença destes altos como frações do em basamento arqueano e eo-proterozóico da região,e que fó ram intensivamente retrabalhados no Ciclo Brasiliano, em especial por rochas graniticas.

o esquema geotectônico regional proposto incorporou vá rios ensaios de zoneamento precedentes, em áreas mais restritas, harmonizando-os com o conceito abraçado de uma complexa região em mosaico, com suas linhas estrutú rais dispostas em leque, cobrindo todo o quadrante nor deste.
\end{abstract}

Abstract: This thesis is the first attempt for geotectonic zoning of the Eastern Northeast region of Brazil, at 1:2,500,000 scale, having as fundamental basis on preexisting geological maps at reconnaissance scales, mostly $1: 250,000$ and lesser ones.

It is proposed a geotectonic scheme based upon the concept of "an ensialic geosynclinal region with mosaic-like arrangement, positioned between two cratonic nuclei, São Francisco (south) and São Luiz (north). In this region, there were identified and named, of an experimental way, all its different geotectonic elements, as median massifs, geanticline zones ("Tectonic highs") and the main fold belts, of marginal and interior/distal types. It is emphasized the role of polycynclinal deep faults as well as the role of the granitic rocks in the complex arrangement of the geotectonic elements of that wide region, during the Brasiliano Cycle.

The preexistent geochronological data were reexamined and a great improvement was done in gathering new data by $\mathrm{K}-\mathrm{Ar}$ and $\mathrm{Rb}-\mathrm{Sr}$ methods, mostly in the so-called tectonic highs. Such data were decisive in order to identify the presence of the tectonic highs that worked out as fragments of the basement, which exhibited Archean and Early Proterozoic ages, and important reworking during the Brasiliano events.

The proposed regional geotectonic scheme has absorved many of the previous essays on this subject, in different and minor areas of Northeast. All these previous works were incorporated in a single one, with the general concept of a complex region, whose structural trends show a fan-like distribution, covering all the northeast quadrangle. 
THOMAZ FILHO, Antonio

Potencialidade do método $\mathrm{Rb}-\mathrm{Sr}$ para datação de rochas sedimenta res argilosas. 22 de julho.

Orientador: Umberto Giuseppe Cordani

Resumo: 0 presente trabalho efetivou-se no sentido de testar a potencialidade da aplicação do método Rb-Sr em sedimen tos argilosos, utilizando amostras de formações paleo zóicas e eo-mesozóicas de bacias sedimentares brasile $\underline{i}$ ras. A intenção residiu na determinação da idade da se dimentação e de eventos diagenéticos posteriores, ocor rentes em unidades sedimentares marinhas e continentais, bem conhecidas do ponto de vista estratigráfico. As pes quisas incluiram os folhelhos marinhos paleozóicos da Formação Trombetas (Membro Pitinga) da Bacia do Amazo nas e das Formações Irati e Estrada Nova da Bacia do Pá raná. Desta última bacia, incluiu-se ainda a Formação Rio do Rasto, continental paleozóica e a Formação Botú catu (Facies Pirambóia), continental eo-mesozóica. Tó das as amostras analisadas provieram de testemunhos de poços perfurados pela PETROBRÁs naquelas bacias.

As análises físicas, químicas e isotópicas de trinta e oito amostras, subdivididas em cento e treze sistemas mineralógicos diferentes, foram efetuadas nos laborató rios do Centro de Pesquisas Geocronológicas da Universi dade de São Paulo. Utilizaram-se amostras em rocha tó tal e em fração fina, com granulação inferior a dois mi crons, bem como frações provenientes do ataque com ácí do clorídrico diluído (lixiviado e resíduo insolúvel). Os resultados obtidos, interpretados segupgo dijagramas
is 8 gonnicos, correlacionando as razões $\mathrm{Sr}^{8} / \mathrm{Sr}^{86} \mathrm{Rb}^{89}$, $\mathrm{Sr}^{86}$, encontram-se na seguinte relação:

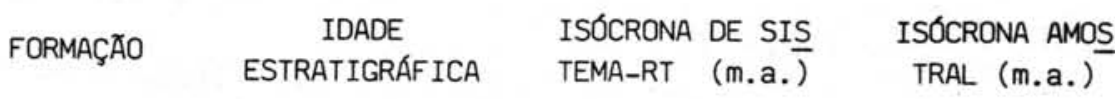

\begin{tabular}{|c|c|c|c|}
\hline Irati & P-Sup. (Kazaniano) & $256 \pm 19$ & $180 \pm 17$ \\
\hline Estrada Nova & P-Sup. (Kazaniano) & $243 \pm 14$ & $177 \pm 5$ \\
\hline Rio do Rasto & $\begin{array}{r}\text { P-Sup. (Kazaniano/ } \\
\text { Tatariano) }\end{array}$ & $228 \pm 9$ & $211 \pm 12$ \\
\hline $\begin{array}{l}\text { Botucatu } \\
\text { (F.Pirambóia) }\end{array}$ & Tr-Médio - J-Sup. & $176 \pm 13$ & $131+4$ \\
\hline $\begin{array}{l}\text { Trombetas } \\
\text { (Mb.Pitinga) }\end{array}$ & $\begin{array}{l}\text { S-Inf. (Landoveria } \\
\text { no) }\end{array}$ & $420 \pm 34$ & $162 \pm 13$ \\
\hline
\end{tabular}

As isócronas do sistema rocha total (RT) indicarama ida 
de absoluta da deposição da unidade sedimentar, semelhan te à idade estratigráfica, segundo a escala do tempo geo lógico. Os dados extraídos da literatura especializada, aliados aos presentes, levaram a interpretações dos pro cessos envolvidos quando da deposição do sedimento, em termos de fenômenos de dispersão uniforme do material de trítico, no meio aquoso deposicional. As razões iniciais obtidas oscilaram entre 0.71 e 0.73 , sendo condicionadas à natureza e idade do material fonte.

As isócronas amostrais, incluindo fração fina, lixivia do e resíduo (em HCl), indicaram idades absolutas de eventos diagenéticos com poder termodinâmico suficiente para produzir a homogeneização isotópica do Sr entre os constituintes mineralógicos inferiores a dois microns. Com base no alcance da homogeneização isotópica do Sr, em termos das dimensões dos minerais envolvidos e do vo lume de rocha implicado, é proposta a introdução de qua tro modelos de diagramas isocrônicos para as rochas se dimentares argilosas:

Modelo isocrônico I - homogeneização isotópica no siste ma-FF, em nível de amostra de mão (isócrona amostral);

Modelo isocrônico II - homogeneização isotópica no sís tema-RT, em nivel de amostra de mão;

Modelo isocrônico III - homogeneização isotópica no sis tema-FF, em nível de unidade de rocha;

Modelo isocrônico IV - homogeneização isotópica no sis tema-RT, em nível de unidade de rocha.

O problema da amostragem é de fundamental importância pa ra a aplicação do método Rb-Sr na datação das rochas se dimentares argilosas. É necessário coletar amostras năo muito afastadas entre si, preferencialmente de uma mes ma camada da unidade sedimentar, com muito baixo teor de material grosseiro, visando a homogeneidade do mate rial detrítico.

Processadas as análises por fluorescência de raio $X$, se lecionar, para análise isotópica, amostras que apresen tem diferentes razões Rb-Sr.

Análises organopalinológicas fizeram ressaltar a viabi lidade da correlação entre os eventos de homogeneização isotópica do $\mathrm{Sr}$ e a maturação da matéria orgânica contí da na rocha sedimentar.

GAMA JUNIOR, Ercílio Gonzaga

Sistemas deposicionais e modelo de sedimentação das Formações Cam pos e Emboré, Bacia de Campos, Rio de Janeiro, Brasil. 22 de jū lho. 104p (2v.)

Orientador: Kenitiro Suguio 
Resumo: Com base em dados de poços de petróleo e de levantamen tos sísmicos de reflexão realizados pela PETROBRÁS, fó ram reconhecidos quatro sistemas deposicionais: Sistema Deltaico Emborê, Sistema Leque Deltaico Guriri, Sistema Plataforma Carbonática Siri e Sistema Talude Continental Campos, na seqüência sedimentar depositada a partir do Cretáceo da Bacia de Campos, Rio de Janeiro.

o Sistema Deltaico Emborê é o gerador dos sedimentos da unidade estratigráfica homônima, constituída por duas principais fácies, cordões litorâneos e barras de distrí butários. Esta unidade genética domina a sedimentação na bacia a partir do oligoceno.

o Sistema Leque Deltaico Guriri é essencialmente repre sentado pela fácies distal e corresponde parcialmente ao Membro Guriri da Formação Campos. Durante a fase de seu maior desenvolvimento, entre o Eoceno e o oligoceno, es te sistema foi alimentado por uma drenagem implantada ao longo do "rift" da Guanabara.

o Sistema Plataforma Carbonática Siri é constituído por dois depósitos; o primeiro, de idade eocênica, parcial mente contemporâneo ao Leque Deltaico Guriri e o segun do, mais desenvolvido, teve o seu maior desenvolvimento durante o Oligoceno.

Finalmente, o Sistema Talude Continental Campos repre presenta a sedimentação de águas profundas, desenvolvi da do Cretáceo Superior até o Plioceno.

As relações estratigráficas e as principais caracterís ticas desses sistemas deposicionais são mostradas em oi to seções sismico-estratigráficas, interpretadas a par tir da correlação com os perfis geofísicos dos poços pro fundos. A metodologia aqui empregada revelou uma exce lente resolução em problemas de análise de bacias sedí mentares submersas e, particularmente, na delimitaçăo de área favoráveis à ocorrência de acumulações de petróleo.

OLIVEIRA, Mary Elizabeth Cerrutti Bernardes de Tafoflora eogondvânica da Camada Irapuá, Formação Rio Bonito (Gru po Tubarão), SC. 13 de maio. 301p. (2v.)

Orientador: Josué Camargo Mendes

Resumo: Esse trabalho teve por escôpo rever e estudar a importan te tafoflora da Camada Irapuá, com base em material prō veniente de 4 afloramentos da região de Criciúma, SC. É a terceira camada de carvão dentre as cinco pertencen tes à Formação Rio Bonito, do Subgrupo Guatá, seqüênciā pós-glacial do Grupo Tubarão, na região catarinense da bacia sedimentar do Paraná.

Fez-se um extensivo estudo sistemático de seus elementos constituintes, registrando-se os seguintes taxa novos: Ponsotheca lobifolia gen. et sp. nov.; Notoangaridium 
.8 .

criciumensis (Rigby) gen. nov.; Arberiopsis boureaui gen. et sp. nov.; (?) Arberiopsis sp. A; (?) Arberiopsis sp. B; (?) Arberiopsis sp. C; Gangamopteris rigbyi sp. nov.; Glossopteris spathulato-cordata (Feistm.) emend. Banerjee \& Ghosh var. dolianitil var. nov.; Rhabdotaenia criciumensis (Dolianiti) n. comb. e Buriadia mendesii sp. nov. Muitas formas já conhecidas de outras regiões gondvânicas são pela primeira vez aqui registradas e outras ainda colocadas em sinonímia. Sua associação tafofloristica, mais ou menos uniforme para toda a porção médio-superior daquela formação, cor responde à Tafoflora "C" de ROSLER (1973).

Apresenta-se como uma flora de Glossopteris, relativamen te pobre em elementos carboniferos nórdicos (Pecopte ris, Sphenopteris) e onde as glossopteridófitas consti tuem cerca de $50 \%$ da associação, $40 \%$ dos quais são ré presentados por elementos do gênero Glossopteris, com uma subordinação nitida de Gangamopteris.

Coloca-se assim entre as assembléias típicas da seqüên cia eogondvânica, pós-glacial, de Permiano Inferior-Mé dio (Artinskiano).

Com base na litologia, na presença de um leaídeo e no tipo de fósseis sugere-se que o paleoambiente deposicio nal da camada fossilifera tenha sido o de planície de inundação.

Fundamentando-se em reconstruções paleogeográficas ela boradas por paleomagneticistas e nas características da própria tafoflora crê-se que o clima predominante, durante a deposição da Camada Irapuá, foi o temperado frio.

BITTENCOURT, André Virmond Lima

Sólidos hidrotransportados na bacia hidrográfica do rio Ivaí: aplicação de balanços hidroquímicos na compreensão da evolu ção dos processos da dinâmica externa. 08 de dezembro. 201p. Orientador: Adolpho José Melfi

Resumo: Com base em dados hidro-químicos e hidráulico tsedimento lógicos são feitas caracterizações das águas da bacia do Ivaí em seus compartimentos: a) Caiuá; b) Basal tos da Fm. Serra Geral; c) Seqüência Paleozóica, quañ to a seu quimismo e aspectos de transporte de sólidos. Para o compartimento basáltico são calculadas taxas de alteração intempéricas e feitos balanços erosão-altera ção.

Dados de erosão química, mecânica e taxas de alteração, obtidos na bacia do rio Ivaí são tentativamente extrapo lados para outros sitios. 
Palinologia da Formação Santana (Cretáceo do nordeste do Brasil).

11 de agosto. 335p.

Orientador: Oscar Rösler

Resumo: Entre as unidades que compõem a seqüência sedimentar me sozóica do Nordeste do Brasil, destaca-se a Formação Sañ tana pelas suas peculiaridades estratigráficas e paleon tológicas. Ao já importante acervo de conhecimento a respeito da mesma, acrescentam-se agora os resultados de um amplo estudo, erigido em bases palinológicas.

0 material que possibilitou a referida pesquisa foi co letado em 12 perfís, distribuídos de modo a cobrir do mé lhor modo possível, as áreas de ocorrência da unidadé nos flancos da bacia.

A parte inicial do trabalho apresenta um estudo relati vamente extenso sobre a unidade em foco, abordada sob os pontos de vista litológico, tectônico e paleontológi co.

No aspecto sistemático, 230 espécies foram identificadas e descritas, incluindo dois gêneros e 24 espécies novas.

o tratamento qualitativo e quantitativo destas microflo ras permitiu o estabelecimento de 4 zonas palinológicas distintas, válidas para todo o âmbito da bacia. Além disso, foi possível, com relativa precisão,efetuar a da tação das mesmas, sendo as 3 zonas mais basais enquadra das no Albiano Inferior e a quarta no Albiano Médio. Foi também estabelecida a correlação estratigráfica da Formação Santana com algumas unidades sedimentares de bacias próximas.

Do ponto de vista paleoecológico, estabeleceu-se a re constituição das modificações ambientais sofridas nas $\overline{3}$ fases distintas ocorridas durante a deposição da unida de, representadas, respectivamente, por uma fase lacus tre, seguida por uma lagunar, e finalmente por outra la custre.

Dados paleogeográficos foram também obtidos, possibili tando a formulação de hipótese relativa à proveniência do mar a partir da Bacia Potiguar. São igualmente dis cutidas as informações disponíveis de outras áreas sedí mentares do Nordeste do Brasil que poderiam representar o registro desta passagem.

Algumas informações de caráter paleoclimático foram tam bém incorporadas, reforçando a idéia de um clima quentē e árido na época de deposição dos sedimentos.

Finalmente, considerações de caráter paleoflorístico tam bém foram efetuadas, mostrando a evolução da vegetaçãō e completando deste modo um quadro geral do ambiente de posicional desta unidade. 
SÁ, José Haroldo da Silva

Pegmatitos litiníferos da região de Itinga-Araçuaí,Minas Gerais. 23 de janeiro. 104p.

Orientador: Reinholt Ellert

Resumo: Na região dos municípios de Itinga e Araçuaí, no médio Jequitinhonha, Nordeste de Minas Gerais, foram estudados mais de uma centena de pegmatitos distribuidos em uma área de aproximadamente $800 \mathrm{~km}^{2}$. Trata-se de um distrí to que contém depósitos de cassiterita e minerais de L $\underline{\underline{i}}$ tio, estes de maior importância econômica, além de quan tidades subordinadas de tantalita-columbita,bem como pe dras semi-preciosas.

Regionalmente predominam quartzo-mica xistos, localmen te ricos em cordierita, com orientação geral NE-SW com mergulhos para NW. Esses xistos, atribuídos ao Grupo Macaúbas, foram intrudidos por plutons de composição gra nítica. Datações geocronológicas, efetuadas pelo méto do Rb-Sr, indicaram idades em torno de 650 milhões de anos para os xistos e 520 milhões de anos para os grani tos. Muscovitas de dois pegmatitos foram datadas pelo método $\mathrm{K}-\mathrm{Ar}$, obtendo-se idades de $467 \pm 18$ e $490 \pm 12 \mathrm{~m} \underline{\mathrm{i}}$ lhões de anos.

Os pegmatitos são classificados em simples e complexos, com base em critérios mineralógicos e estruturais. Os pegmatitos simples são constituídos de feldspato (micro clíneo), quartzo e muscovita; acessoriamente encontrase berilo e turmalina (afrisita). Nos pegmatitos com plexos além dos minerais dos pegmatitos simples, há uma notável associação mineralógica acessória, na qual se destacam os minérios de Lítio (petalita, espodumênio, le pidolita e ambligonita), de Césio (polucita), cassiter ta, tantalita-columbita, além de uma grande variedade de turmalinas. Os pegmatitos do tipo complexo concen tram, preferencialmente, uma das formas mineralógicas do Litio, tais como: pegmatitos com petalita, pegmatitos com espodumênio, pegmatitos com lepidolita e pegmatitos com polucita-espodumênio.

Os pegmatitos simples afloram com formas tabulares, fre qüentemente exibindo um zoneamento textural interno de vido ao aumento da granulação que cresce da borda para o centro. Nos complexos, as formas mais comuns se apro ximam do tipo lenticular, mostrando internamente distin to zoneamento textural e mineralógico. Os pegmatitos com espodumênio, que se apresentam com formas tabulares, exibem estrutura interna praticamente homogênea.

os pegmatitos do tipo simples estão distribuídos em toda área, preferencialmente nas bordas dos maciços graníti cos, bem como nos xistos. Os tipos complexos estão en caixados nos xistos e mostram arranjo zonal; os pegmat $\underline{i}$ tos com petalita estão mais próximos dos maciços de gra nito e, mais distanciados estão os portadores de lepido 
lita e exibem o maior grau de complexidade estrutural e mineralógica.

A orientação dos pegmatitos é discordante em relação aos xistos encaixantes, tendo-se alojado, por um proces so de intrusão, dentro de espaços abertos naquelas ró chas.

Geneticamente os pegmatitos estão relacionados com os granitos da região que apresentam elevados teores de Lí tio, Césio e Berílio quando comparados com granitos nor mais da crosta. Análises das relações Rb-K e Cs-K em feldspatos potássicos dos diferentes pegmatitos, mostra ram um progressivo aumento destas relações, sendo os maiores valores encontrados nos feldspatos dos pegmat $\underline{i}$ tos mais complexos.

Conclue-se que os pegmatitos foram formados, nos primei ros estágios, através de sucessivas cristalizações de frações residuais do magma granítico, com progressivo enriquecimento em Litio e, nos estágios mais tardios, através de processos metassomáticos, responsáveis pela formação dos pegmatitos mais complexos.

SARTORI, Pedro Luiz Pretz

Petrologia do Complexo Granítico de São Sepé, RS: modelo evolu cional de granitos do sul do Brasil. 26 de setembro. 196p. Orientador: Nabor Ricardo Rüegg

Resumo: A geologia do Complexo Granítico de São Sepé, localiza do na região do Escudo Sul-rio-grandense, Rio Grande do Sul, foi levantada em pormenor.

Rochas básico-ultrabásicas do Complexo Pedras Pretas, embutidas na extremidade sul do referido maciço graníti co, exibem idade mínima de um bilhão de anos correlacio nável com eventos transamazônicos a que se associam ró chas similares das localidades de Mata Grande,Cerro Man tiqueiras e outras da parte ocidental do Escudo.

Rochas metamórficas encaixantes do Batólito de São Sepé, exibem, em conseqüência da ação intrusiva, auréola de hornfelses pelíticos, equivalentes, na zona mais inter na, à fácies hornblenda-hornfels.

$\mathrm{Na}$ borda leste-sudeste do corpo granítico, rochas sedi mentares da Formação Maricá e vulcanitos de composição andesito-basáltica da Formação Hilário também registram, do ponto de vista mineralógico e geocronológico, evidên cias de metamorfismo de contato.

Petrograficamente, o Complexo Granitico de São Sepé é formado por rochas distintas. Na parte centro-sul, des taca-se um microgranito porfiritico e na parte centronorte, um granito monzonitico porfiritico. A rocha que as envolve, corresponde a um granito sub-alcalino equi granular exibindo decréscimo na granulação em direção às bordas do Complexo. Intrusões menores são represen 
tadas, principalmente, por microgranitos álcali-feldspá ticos.

Determinągós radiométrifcas, pęlo método rubídio-estrôn cio $\left(\lambda \mathrm{Rb}^{8}=1,47 \times 10^{-1}\right.$ anos $\left.^{-1}\right)$, forneceram a idade de $646 \pm 6 \mathrm{~m}$.a. para as rochas granito-monzoníticas da parte central do Complexo Granítico, correspondendo à fase sintectônica do Ciclo Brasiliano. 0 granito sub-alcalino periférico acusou idade de $507 \pm 7 \mathrm{~m}$.a. e os microgranitos álcali-feldspáticos de intrusões menores e os riólitos alcalinos do Cerro Tupanci, indicaram idade de $450 \pm 6$ m.a., compatíveis com a fase pós-tectônica do referido ciclo orogênico.

Os dados até aqui reunidos mostram, portanto, que as ro chas granito-monzoniticas, descritas em outros complexos graníticos da região do Escudo Sul-rio-grandense, guar dam relação com as que ocupam a parte central do Comple xo de São Sepé e apresentam idades correlacionáveis à fá se sin-tectônica do Ciclo Brasiliano. Por outro lado, os granitos sub-alcalinos, de textura granular, que se associam às anteriores ou formam plutões independentes, estão ligados à fase pós-tectônica do referido Ciclo. A heterogeneidade na composição de vários maciços graní ticos, descritos ao longo da Região Orogênica do Sudes te, indica que eles sofreram evolução geológica segundo moldes semelhantes, em área de embasamento siálico favo ráveis à geração de granitos por anatexia, durante in tervalo de tempo significativo, no decorrer do Ciclo Brä siliano.

Abstract: Detailed petrological studies of the granitic complex of São Sepé, located in the region of Sul-rio-grandense shield, state of Rio Grande do Sul, Brazil, were made. Basic-ultrabasic rocks of the Pedras Petras Complex, located in the southern part of the granitic massif, have minimum age around one billion years, related to the Transamazônico orogenic cycle, to with are associated similar rocks of the localities of Mata Grande, Cerro Mantiqueiras and others of the western part of the Shield.

Metamorphic country-rocks, around the western part of the batholith of São Sepé, was affected by thermal metamorphism and exhibit an aureola of meta-pelitic rocks equivalent, in the inner-part, to the hornblende-hornfels facies.

The complex of São Sepé is composed by granitic rocks of different composition. In the central-southern part, there is a microgranite-monzonitic porphyritic and in the central-northern part a granite-monzonitic porphyritic. The rock around them, correspond to a sub-alkaline granite, with granular texture, displaying decrease in granulation to the margin of the Complex. Small intrusions are 
represented, principally, by alcali-feldspatic microgranites. Radiometric ages, by rubidium-strontium total rock isochrons ( $\lambda \mathrm{Rb}^{\mathrm{O}}=1,47 \times 10^{-11}$ years), yielded an isochron age of $646 \pm 6 \mathrm{~m} . \mathrm{y}$. for granitic-monzonitic rocks of the central part of the granitic complex, corresponding to the synkinematic stage of the Brasiliano orogenic cycle. The sub-alkaline granite provided an isochron age of $507 \pm 7 \mathrm{~m} . \mathrm{y}$. and the alkali-feldspatic microgranites of small intrusions, together with alkali-rhyolites of Cerro Tupanci, gave an age of $450 \pm 6 \mathrm{~m} . \mathrm{y}$. , related to the postkinematic stage of the Brasiliano orogenic cycle. From what is said above, as far as can be deduced from observations made during this work, the graniticmonzonitic rocks, described in other granitic complexes of the Sul-rio-grandense shield, are related with the rocks that are located in the central part of the sao Sepé Complex and have ages correlated to the synkinematic stage of the Brasiliano tectonic cycle. On the other hand, the sub-alkaline granites, of granular texture, that are associated with the first ones or occur like independent plutons, are related to the postkinematic stage of the same tectonic cycle.

The heterogeneity in composition of many granite massifs that are allocated in the sudeste orogenic region, Southern Brazil, show that they had a geological evolution at similar way, in areas of sialic embasement favorable to granitic generations by anatexis, during the development of the Brasiliano tectonic cycle.

BARCELOS, José Humberto

Arenitos cretáceos do Alto Paranaíba, MG: proveniência e ambien tes de sedimentação. 21 de dezembro. 181p.

Orientador: Kenitiro Suguio

Resumo: No Alto Paranaíba, oeste do Estado de Minas Gerais, ocor rem quatro formações sedimentares depositadas em ambien te fluvial e influenciadas por atividades vulcânicas a calinas.

A Formação Areado é a mais importante entre elas, tendo sido estudada em relação ao seu ambiente deposicional. Os sedimentos dessa idade são essencialmente fluviais e foram reconhecidos depósitos associados a planícies de inundação e a subambiente de canais fluviais. Esses se dimentos parecem ter sido depositados em um sistema flü vial que mudou de meandrante pelítico a psamítico em fun ção do paleoclima durante a sua sedimentação.

Estudos sedimentológicos envolvendo análises granulomé tricas, minerais pesados e minerais de argila foram rea 
.14 .

lizados em 171 amostras coletadas na Formação Areado. Litologicamente, esta formação é constituída de areni tos finos a muito finos, sílticos, raramente conglomerá ticos. Mineralogicamente são imaturos e a assembléia de minerais pesados, formada de estaurolita, epídoto, cia nita e granada, indica que as rochas matrizes desses se dimentos pertenciam aos Grupos Araxá, Canastra, Bambuí, além da Formação Botucatu.

CERRI, Carlos Clemente

Alteração e pedogênese em áreas graníticas situadas sob diferen tes condiçбes bioclimáticas encontradas no Brasil. 11 de junho. $214 \mathrm{p}$.

Orientador: Adolpho José Melfi

Obs.: Resumo e abstract não disponíveis.

FIORI, Alberto Pio

Geologia da região de Pouso Alegre - Machado: análise estrutural de dobramentos supepostos. 30 de novembro. 200p.

Orientador: Paulo Milton Barbosa Landim

Obs.: Resumo e abstract não disponíveis.

FURTADO, Valdenir Veronese

Contribuição ao estudo da sedimentação atual no canal de São Se bastião, Estado de São Paulo. 09 de abril. 110p. (2v.)

Orientador: Kenitiro Suguio

Resumo: 0 trabalho tem como objetivo contribuir para o entendi mento do processo dinâmico da sedimentação atual no Cá nal de São Sebastião, SP, procurando-se estabelecer a interação entre o comportamento hidrodinâmico e a distri buição superficial dos sedimentos. Para tal foram rea lizados: a) análise sobre a fisiografia do canal atrá vés de cartas batimétricas e perfis de ecossondagem; b) estudos sobre o comportamento hidrodinâmico pela análi se de parâmetros oceanográficos costeiros; c) análises sobre a distribuição sedimentar através do estudo de pa râmetros físicos, químicos e mineralógicos dos sedimen tos de superfície de fundo. Obteve-se, como resultado, um modelo de dispersão de sedimentos que, associado a me dições hidrodinâmicas, permitiu sugerir um padrão geral de circulação para a área.

o Canal de São Sebastião possui uma direção SW-NE, com duas entradas onde se destacam duas feições sedimenta res. A porção sul apresenta uma feição tabular, forma da por areias finas e muito finas, bem selecionadas é com baixa ocorrência de pelitos. Esta feição pode ser atribuída à ação de ondas no fundo marinho local. Na porção norte observa-se um banco submerso, formado por 
areias com crescimento no sentido NE, função de fluxo, predominantemente unidirecional, nesse sentido. Este pode ser atribuída à aceleração local do fluxo.

Há, no Canal de São Sebastião, uma tendência à maior de posição no lado continental e pontos de maior erosão no lado insular, como conseqüência da dinâmica natural da área.

A origem dos sedimentos de superfície do fundo do Canal de São Sebastião pode ser atribuída à ação marinha nas rochas costeiras, ao retrabalhamento do fundo do canal e da plataforma continental adjacente e ao aporte de pe litos oriundos da descarga do rio Juqueriquerê.

HARALYI, Nicolau Ladislau Ervin Carta gravimétrica do Oeste de Minas Gerais, Sudeste de Goiás e Norte de Såo Paulo. 17 de outubro. 152p. Orientador: André Davino

Resumo: Algumas milhares de estações de gravimetria levantadas pelo IBGE - Fundação Instituto Brasileiro de Geografia e Estatística, pelo Observatório Nacional do Rio de Ja neiro, pela PETROBRÁS e por projetos locais feitos por outras Universidades, pelo DNPM e por algumas empresas de mineração, permitiram ao autor levar a efeito a exe cução de uma carta gravimétrica de tendência Bouguer e a uma tentativa de interpretação em termos da evolução geo tectônica de considerável área da região oriental do Brasil.

No presente trabalho 4103 estações gravimétricas foram utilizadas, das quais 1984 localizam-se dentro da área limite estudada.

A área pesquisada, situada na região centro-meridional do Brasil, contém grande número de estações de gravime tria referenciadas ao sistema internacional, na área do chamado "DATUM DO CHUÁ", abrangendo a região do Triângu lo Mineiro, norte do estado de São Paulo, além de parté do sudeste do estado de Goiás.

As coordenadas limites dessa área são $45^{\circ}$ a $51^{\circ} \mathrm{W}$ e $17030^{\prime}$ a 21030 's. Excetuam-se as zonas com baixa densidade de pontos, entre as coordenadas $50^{\circ}$ a $51^{\circ} \mathrm{W}$ e $17^{\circ} 30^{\prime}$ a $18^{\circ} 00^{\prime} \mathrm{S}$; $50^{\circ} 30^{\prime}$ a $51^{\circ} \mathrm{W}$ e $18^{\circ} 00^{\prime}$ a $19^{\circ} \mathrm{S}$; $45^{\circ}$ a $46^{\circ}$ e $17^{\circ} 30^{\prime}$ a $18^{\circ} \mathrm{S}$. Abrange parte da faixa definida para o programa Brasi leiro de Geodinâmica.

A consistência dos dados, cálculos e contorno das cur vas isogal foram feitas em computador eletrônico empré gando o método de ajuste, aos dados, de superfície poli nomiais por minimos quadrados.

Tal área é coberta, parcialmente, pelos levantamentos aero-geofísicos (magnetometria e cintilometria), executa dos pelo Convênio Geofísica Brasil-Alemanha, o que fací litou a interpretação geológica dos dados gravimétricos. 
.16.

A escala de tais cartas é de 1:100.000, executada por aero-levantamentos em altitude fixa, com as linhas de vôo, no sentido $\mathrm{E}-\mathrm{W}$, espaçados de $2 \mathrm{~km}$. Algumas áreas foram detalhadas por vôos com helicóptero, das quais a folha de Monte Carmelo I já tem relatório concluído.

Como apoio geológico, a área foi mapeada por diversos autores e entidades, cujos mapas permitem correlacionar as anomalias gravimétricas verificadas com as estruturas mapeadas.

Ressalta-se ainda que parte da área estudada foi recen temente objeto de detalhado levantamento gravimétrico pé la Missão Franco-Brasileira de Gravimetria (Convênio CNPq-DNPM/CPRM-CNRS-ORSTOM-IGUSP). Quando disponíveis estes dados gravimétricos deverão permitir o traçado mais detalhado da carta gravimétrica, inclusive na esca la de reconhecimento de 1:500:00 ou 1:250.000.

Geologicamente a área objeto da presente pesquisa compre ende a Bacia Sedimentar do Paraná a o Embasamento Cris talino; sedimentos mesozóicos cobrem em pequenas áreas - Embasamento Cristalino.

As feições tectônicas existentes na área estudada, como flexuras, arqueamentos, extensas zonas de falhas, depres sões locais, etc. são ressaltadas e meihor delimitadas na carta gravimética.

São também definidas algumas zonas de falhamentos pro fundos, de idades muito antigas, reativados diversas vé zes nos tempos geológicos, ao longo dos quais houve con dições para as intrusões de corpos profundos e mesmo or $\underline{\underline{i}}$ ginados no manto superior (Kimberlitos) e que são respon sáveis por mineralizações de interesse econômico.

Abstract: This thesis concerns with the elaboration of the Bouguer Gravity Chart in a $23 \frac{1}{2}$ square degrees area located in the central-meridional region of Brazil.

The major units involved in the area are the NE part of the Paraná Basin, a small part of the SE border of São Francisco cratonic area and the remaining crystalline basement, including the Central Transbrasilian Arch. It covers also part of the Brasilian Geodynamic Project's area.

Some tectonic structures as like the Goiania flexure and large fault zones could be delimitated and finally some light has been added to the history of the tectonic evolution of the area.

SEIGNEMARTIN, Cláudio Lisias

Geologia de áreas urbanas: o exemplo de Ribeirão Preto, SP. 22

de novembro. 126p. (2v.)

Orientador: Vicente José Fúlfaro

Resumo: De algum tempo a esta parte, vem sendo notado um inte 
resse crescente entre os geólogos brasileiros, para os problemas de preservação do meio ambiente como um todo, e do meio físico em particular. Essas idéias, no entan to, fruto da influência exercida por profissionais es trangeiros, especialmente da área da Geologia de Engenhá ria, cresceram mal dirigidas e voltadas unicamente para interesses mais imediatos, por erros nacionais de enfo que e interpretação, tanto a nível técnico,quanto empre sarial e governamental, inclusive no que diz respeito à própria essência da Geotécnica ou Geologia de Engenha ria.

Tendo acompanhado de perto o desenvolvimento dessas ten dências, o autor vê com certa preocupação o futuro dessá área das geociências no país, sendo no seu entender, ne cessário que haja uma reflexão, uma volta crítica às ra zes, às origens dos problemas de utilização racional do ambiente, que são eminentemente do meio físico e, portan to, geológicas.

Tomando por base esse princípio, procura-se firmar, na parte inicial do trabalho, uma série de conceitos que podem trazer alguma contribuição ao assunto, reabilitan do o termo Geologia Ambiental e introduzindo a expressão Geologia de Áreas Urbanas. É também enfatizado o cará ter multidisciplinar do planejamento urbanoe, a seguir, discutidas as principais correntes metodológicas, justi ficando-se a escolha da apresentada por SANEJOUAND (1972), a cartografia geológico-geotécnica, com a adoção das cartas de documentação, de fatores e de síntese, além do documento final, de caráter recomendativo quanto ao uso do terreno disponível.

A segunda parte, é uma tentativa de demonstração da va lidade prática das idéias apresentadas, associando dados geológicos e dados geotécnicos, com a finalidade de for necer uma base para estudos de planejamento do uso do meio físico natural. Assim, como área-teste, foi escolhido um centro urbano em processo acelerado de desenvolvimen to, face ao agravamento das solicitações impostas ao meio ambiente, como na intensificação da busca de solu ções que se impõe, imediata.

Uma vez determinada a área, parte do município de Ribei rão Preto, estado de São Paulo, e conhecida sua proble é mática através da confecção das Cartas de Fatores e de Aptidão, foi estabelecido um zoneamento que indica,fren te ao Coeficiente do Potencial de uso do terreno, as áreas preferenciais para a ocupação urbana sob o ponto de vista da geologia (Carta de Recomendações de Uso do Meio Físico).

Fica claro que, embora esteja diretamente inserido no contexto dinâmico do planejamento como uma de suas par tes básicas, este trabalho não se constitui em um traba lho global sobre planejamento urbano, mas é um subsídio 
.18 .

imprescindivel à complexa tarefa de ordenar a ocupação das áreas disponíveis à expansão de um determinado aglo merado urbano.

SOUZA, José Vitorino de

Geologia e gênese do protominério e do minério da província man ganesífera de Aracoiaba-Pacajús, no Estado do Ceará. 16 de abril. $167 p$.

Orienador: Evaristo Ribeiro Filho

Resumo: Este trabalho foi desenvolvido principalmente nas locali dades de Serragem e Lagoa do Riacho no município de Ara coiaba, CE, abrangendo também, em alguns aspectos, toda a província manganesífera de Aracoiaba-Pacajús no nor deste do Estado do Ceará.

o trabalho tem como objetivo principal a caracterização paragenética e textural do protominério oxidado de man ganês a fim de definir sua gênese e intemperismo.

A litologia regional é formado por migmatito-gnaisse, granada-silimanita-quartzitos e metabasitos. De manei ra restrita são encontrados gonditos alterados juntamen te com granada-quartzitos encaixados no migmatito-gnais se cortado por pegmatitos homogêneos.

0 gondito, de direção $\mathrm{N} 20^{\circ} \mathrm{W}$ e mergulho de $50^{\circ}$ a $75^{\circ}$ para leste, foram situados estrutural e estratigrafica mente no Complexo Caicó.

o metamorfismo regional é de fácies granulítica com su perimposição de fácies anfibolito com pressão e tempera tura mínima respectivas de $6 \mathrm{~kb}$ e $600^{\circ} \mathrm{C}$.

o gondito é composto essencialmente de espessartita, quartzo, rodonita e mangano-cumingtonita e acessoriamen te de grafita, pirita e pirrotita.

o gondito foi originalmente depositado em bacia restrí ta de ambiente redutor; em seguida foi submetido a, pé 10 menos, duas fases de metamorfismo. Posteriormente, foi submetido a intemperismo formando minério oxidado constituído de litioforita, criptomelano, pirolusita e mangano-nsutita.

As principais texturas do gondito aqui descritas são: textura em mosaico, textura bandeada (deposicionais) e texturas reliquiares, de borda, coloformes, nodular con cêntrica, em retalhos, brechada, filiforme, em pente $\bar{e}$ em boxwork (pós-deposicionais).

Em função das texturas foram configurados três proces sos de formação do minério: processo de substituição, processos de preenchimento de cavidades e de laterizaçăo. Os minérios foram classificados como minérios "in situ" (afloramentos de gondito alterado) e minérios residuais (blocos rolados e esferas concêntricas).

o teor de minério varia de 18 a $38 \%$ de $M n$, sendo o teor médio da província de $23 \%$ de $\mathrm{Mn}$. Isoladamente, as ocor 
rências de Serragem e Lagoa do Riacho têm um teor médio de $28 \%$ de $M n$.

A tonelagem para a província é baixa. O maior depósito (Lagoa do Riacho) possui uma reserva medida de $370.000 \mathrm{t}$ de minério bruto a $28 \%$ de $M n, 50 \%$ das quais são de miné rio residual.

Tendo em vista o baixo teor e a pequena reserva, con clui-se que o minério é aproveitável economicamente em pequenas siderurgias próximas aos depósitos.

Abstract: The manganese deposits of Aracoiaba-Parajus 'district are located in northeast of the State of Ceará,Brazil. The protore and the ore of some of the manganese deposits studied occur between belts of manganiferous rocks extending 60 by $15 \mathrm{~km}$.

The Precambrian regional rocks consit of gneisses,garnetsillimanite-quartzites, metabasites and some pegmatites. These are the host rocks of the manganiferous rocks. All these rocks belong stratigraphically and structurally to the Caicó Complex and are part of the Jaguaribeana folding belt. The silicatic protore is composed of spessartite, rhodonite, quartz, mangano-cumming-tonite with subordinated amounts of pyrite and pyrrhotite. The granulite facies of the regional metamorphism was superimposed by amphibolite facies. The original sediments which altered to form the protore were deposited in a restrict basin of reducing condition and underwent the action of two different phases of metamorphism. Surface weathering altered the protore forming an ore consisting of an assemblage of manganese oxides such as lithiophorite, pyrolusite, mangano-nsutite and $\alpha \mathrm{MnO}_{2}$. The ore presents typical depositional and pos-depositional textures, which show that the ore formed by replacement and cavity filling. The manganese content of the ore varies from 18 to $38 \%$. The reserves of the district are 2.500 .000 metric tons, making economic exploitation viable with a small, local siderurgical industry of Cea rá. The manganese minerals were formed according to the following sequence: spessartite,lithiophorite and/ or cryptomelane, manganite, pyrolusite, mangano-nsutite.

Geologia ambiental. 11 de abril. 73p. Orientador: Nelson Ellert

Resumo: A ocupação do meio físico em geral e a criação de cen tros urbanos em particular têm uma relação estreita com 
o ramo da geologia dita Ambiental, cuja preocupação pre ponderante é a preservação geoecológica. Trata-se dé uma ciência fundamentalmente interdisciplinar, não sen do portanto possivel nem recomendável que um especialís ta pretenda enfocar com profundidade o conjunto de có nhecimentos envolvidos.

Vários pesquisadores nacionais têm publicado artigos so bre o assunto, mormente calcados em autores europeus e norte americanos, enfocando mais aspectos de geotecnia. Neste trabalho procuramos dar um enfoque mais hidrogeo lógico. Com efeito, analisaremos o vetor águas subter râneas nos seus aspectos de recursos que devem ser pre servados contra os riscos engendrados pela implantação de um complexo urbano.

A área escolhida representa uma amostra dos principais litofácies da Bacia do Paraná, indo desde a Formação Es trada Nova até a Formação Bauru, localizada no quadrilá tero formado pelas cidades de Brotas, Itirapina, Santa Maria da Serra e São Pedro, todas no Estado de São Pau 10. É uma zona ainda pouco ocupada, mas que se cogita aí implantar um importante núcleo urbano. Ressaltamos os fatores limitantes com vistas à ocupação no intuito de preservar o meio ambiente em geral e as águas subter râneas em particular.

Este trabalho não representa por si só um estudo sobre os múltiplos aspectos da ocupação de áreas por aglomera dos urbanos, mas é um documento de base que deve ser con sultado para um planejamento racional integrado.

OL IVEIRA, Sonia Maria Barros de

Alteração intempérica das rochas ultrabásicas de Santa Fé, Go, e gênese do depósito niquelífero.

Orientador: Adolpho José Melfi

Resumo: O depósito niquelífero de Santa Fé-Goiás é produto do intemperismo de um maciço ultramáfico-alcalino. A pai sagem consiste de baixadas (Ciclo Velhas - Quaternário Inferior) e morrotes que representam restos da superfí cie Sul-Americana (Terciário). Os perfis de alteração nas baixadas são espessos e apresentam quatro horizon tes: rocha alterada, saprolito grosseiro, saprolito fi no e laterita vermelha. Os silicatos magnesianos evoluem em goethita e hematita.

A evolução geoquímica do perfil laterítico nas baixadas leva à lixiviação do $\mathrm{Si} e \mathrm{Mg}$ e à retenção do $\mathrm{Fe}, \mathrm{Al}, \mathrm{Cr}$, $\mathrm{Mn}, \mathrm{Cu}$ e Co. $\mathrm{O} \mathrm{Ni}$ tem um comportamento intermediário. A partição dos elementos entre os minerais é apresenta da para cada horizonte de alteração. O Ni está associa do principalmente às fases silicatadas (serpentina he $\underline{r}$ dada e amorfos silico ferruginosos).

Nos morrotes aflora a rocha fresca ou silicificada. O 
evento da silicificação é relacionado ao ciclo Sul-Ame ricano e ocorreu na base dos antigos perfis de alterá ção. Mais tarde, com o desmantelamento da superfície Sul-Americana, os morrotes emergiram capeados pela cama da de silica. Os produtos de intemperismo removidos pé la erosão foram a fonte da laterita vermelha das baixa das.

O depósito de Santa Fé é comparado com outros congêneres no mundo.

Abstract: The nickeliferous deposit of Santa Fé, GO, is the product of the weathering of an ultramafic-alkaline massif. The landscape consists of lowlands (Velhas Cycle-Early Quaternary) and hills that are relicts of the SouthAmerican surface (Tertiary). Weathering profiles are thick in the lowlands with four layers: altered rocks, coarse saprolite, fine saprolite, and red laterite. Magnesian silicates evolve to goethite and then to hematite.

The geochemical evolution of the lateritic profile in the lowlands leads to leaching of $\mathrm{Si}$ and $\mathrm{Mg}$ and retention of $\mathrm{Fe}, \mathrm{Al}, \mathrm{Cr}, \mathrm{Mn}, \mathrm{Cu}$ and $\mathrm{Co}$. Ni shows an intermediate behavior. Partitioning of elements among minerals is computed here for each stage of weathering.Ni is mainly associated with silicate phases (inherited serpentine and amorphous Si-Fe products).

On the hills, fresh and/or silicified rocks crop out. The silicification event is related to the South American cycle and occured at the bottom of Tertiary profiles. Later, with the dismantling of the South American surface, the hills emerged capped by the silica layer. The removed weathered products were the source for the red laterite in the lowlands.

The deposit of Santa Fé is compared with other lateritic nickeliferous deposits in the world.

1981

CAMPOS, Jayme de Oliveira

Propriedades geotécnicas e comportamento tecnológico de arenitos na Formação Caiuá. 12 de junho. 251p.

Orientador: José Eduardo Siqueira Farjallat

Resumo: As propriedades geotécnicas e o comportamento tecnológi co das rochas sedimentares brandas não têm sido devidá mente estudadas, no país ou no exterior, apesar da suá grandes importância.

A construção de obras civis de porte, principalmente hi drelétricas, exige a utilização de enormes volumes de materiais de construção, solicita as fundações com car 
.22 .

\begin{abstract}
gas de vulto e impõe alterações no meio físico, respon sáveis por variações acentuadas nas propriedades dos ma teriais utilizados. A utilização de rochas mais bran das, consideradas menos nobres que as rochas mais duras, está se tornando uma necessidade premente na construção destas obras, tendo em vista a responsabilidade de se manter a relação custos/benefícios em níveis razoáveis. Mesmo para pequenas obras, cuja implantação cada vez mais se justifica, técnica e economicamente a utiliza ção de rochas mais brandas deve ser sempre considerada como possivel alternativa.

Os Arenitos Caiuá, rochas sedimentares de ocorrência sig nificativa, particularmente na região sudoeste do Esta do de São Paulo, mas também no norte e nordeste do Pará ná e sul de Mato Grosso do Sul, representam justamenté os materiais que motivaram o interesse exposto. Numa região onde se constroem importantes obras civis e sem rochas duras, tais como basaltos, de ocorrência escassa, o aproveitamento destes arenitos merece ser cuidadosamen te estudado.

Os seguintes aspectos foram tratados neste trabalho:

1. Mineralogia, petrografia, gênese, cimentação, ambien te e deposição.

2. Compartimentação tipológica qualitativa destes mate riais, anisotropia textural e estrutural.

3. Propriedades físicas, granulometria, massa específi ca, porosidade, saturação dos vazios.

4. Ensaios visando avaliar a durabilidade dos arenitos ou ensaios de alterabilidade.

5. Propriedades geomecânicas dos arenitos, resistência, deformabilidade.

6. Análise do aproveitamento dos arenitos, normas, espe cificações, ensaios e critérios de utilização.

Trata-se, em resumo, de um trabalho bastante original e inclue ao mesmo tempo dados de investigações científi cas e aplicaçoes práticas do conhecimento geológico.
\end{abstract}

1982

MELLO, Everaldo Zeferino Vieira de

D-022

Estudo da ocorrência de fluorita, barita e metais básicos da Fa zenda Jurema, Barra da Estiva, Bahia. 01 de dezembro. 221p. Orientador: Reinholt Ellert

Resumo: A regiåo mapeada constitui-se quase que exclusivamente de rochas precambrianas complexamente deformadas e que foram submetidas a diferentes graus de metamorfismo, des de a fácies xisto-verde até a granulito. Tais rochas pertencem, na sua maioria, aos Complexos Granulitico, Metamórfico-Migmatítico e Metamórfico que fazem parte 
do embasamento do Cráton do São Francisco. A luz dos da dos geocronológicos conclui-se pela contemporaneidade dos dois primeiros complexos, com registros radiométri cos do Ciclo Jequié e mais antigos, com retrabalhamento no Ciclo Transamazônico.

- Complexo Metamórfico apresenta traços característicos de "greenstone belt", onde foram individualizados os Gru pos "Greenstone" (Unidade A, B e C) e Sedimentar (Unida de D). Valores entre 2.200 e $1.700 \mathrm{~m} . a$. , do Transamazô nico, são encontrados nos metassedimentos, vulcânicas e rochas graníticas intrusivas. A área onde se efetuou a pesquisa para sulfetos metálicos encontra-se situada geo logicamente na Unidade A, mais inferior, do Grupo "Green stone".

Dois tipos de jazimentos minerais foram constatados: o estratiforme e o filoneano. 0 primeiro é singenético e ocorre em xistos no contato com lente de mármore dolomí tico, com arsenopirita, pirita, calcopirita e pirroti ta, nessa ordem de cristalização. O segundo tipo conn siste de concentrações endógenas epigenéticas formadas pela lixiviação das rochas vulcano-sedimentares por so luções hidrotermais, num processo decorrente de um meta morfismo sin a tarditectônico de fácies xisto-verde. E $\underline{s}$ ses veios preenchem planos de falhas reativadas e têm uma paragênese primária constituída de quartzo, fluorí ta, barita, pirita, esfalerita, calcopirita e galena, nessa ordem de cristalização, e uma secundária formada por goethita, lepidocrocita, covelita, calcocita, mala quita, azurita, famatinita, cerussita, anglesita e cal cita. As pesquisas realizadas revelaram o caráter antie conômico desses depósitos. Na região, os únicos veios explorados são os de barita, por garimpagem.

Através de análise petroquímica, constatou-se que o ti po de depósito sulfetado estratiforme encontra-se inti mamente associado a rochas vulcânicas metamorfoseadas que possuíam um caráter predominantemente subalcalino, pertencentes às séries calco-alcalina e toleítica e com predominância das variedades basálticas e andesíticas sobre as daciticas e rioliticas. Essas atividade vulcâa nica foi se tornando de máfica para félsica e mais áci da à medida que atingia o topo da seqüência.

Abstract: The studied region is almost entirely composed of Precambrian rocks that were deformed in a complex manner and submitted to different metamorphic grades, ranging from greenschist to granulite facies. Most rocks are part of the so-called Granulitic, Metamorphic-Migmatitic and Metamorphic Complexes that form the São Francisco craton basement. The geochronological data show that the first two complexes are contemporaneous as evidenced by the radiometric records of the Jequié Cycle and older 
records; these data also evidence that reworking took place in the Transamazonic Cycle.

The Metamorphic Complex presents features of a greenstone belt, where the Greenstone ( $A, B$ and $C$ units) and Sedimentary ( $D$ Unit) Groups were individualized. Age values between 2,200 and $1,700 \mathrm{~m}-\mathrm{y}$. , of the Transamazonic Cycle, were found in the metasedimentary, volcanic and intrusive granitic rocks. The area where the research was conducted on metallic sulphides is geologically situated in the A Unit, the lowest of the Greenstone Group.

Two types of ore body were observed: the stratiform and the veinform types. The former is syngenetic and occurs in schists in the contact with a dolomitic marble lens, with arsenopyrite, pyrite, chalcopyrite and pyrrhotite, following this sequence of crystallization. The second type consists of epigenetic endogenous concentrations formed by the leaching of the volcano-sedimentary rocks through hydrothermal solutions, such process resulting from a syn- to tarditectonic metamorphism of greenschist facies. These veins are filling up fault planes and have a primary paragenesis of quartz, fluorite, barite,pyrite, sphalerite, chalcopyrite and galena, in this sequence of crystallization. A second paragenesis is formed by goethite, lepidocrocite, covellite, chalcocite, malachite, azurite, famatinite, cerussite, anglesite and calcite. The researches show that these deposits have no economic value. Throughout the region, the only mined veins are those of barite, by rudimentary process.

MUSSA, Diana

Lignitafofloras permianas da Bacia do Paraná, Brasil (Estados de São Paulo e Santa Catarina). 09 de agosto. 553p. (2v.)

Orientador: Antonio Carlos Rocha Campos

Resumo: Os espécimes de lenho fóssil concentram grande potencial de informaçóes, seja sobre o ambiente de vida da planta, seja sobre o ambiente de sedimentação. Daí resultou o enfoque inicial sob o prisma da tafonomia e, posterior mente, sob o prisma da anatomia, sistemática e ecológi ca. Com isso procurou-se a montagem de um método de es tudo voltado somente para os lenhos fósseis.

os resultados do estudo tafonômico são preliminares. Re presentam um ensaio do método, a partir da premissa de que o tempo de vida da planta, a sedimentação das res pectivas seqüências e, no mínimo, os primeiros eventos da fossilização, transcorreram nos limites de um mesmo ciclo deposicional. Da mesma maneira, os mesmos agentes que atuaram durante o referido ciclo interferiram sobre a planta, em vida, e "post-mortem", durante as fases da fossilização. As correspondências existentes merece 
ram averiguações. Até o presente as investigações paleo anatômicas eram conduzidas da mesma maneira que para os lenhos recentes, resultando uma lacuna no terreno da es tratigrafia e a polarização no campo da sistemática for $\underline{r}$ mal. Os resultados do estudo tafonômico deixam entré ver sua profícua aplicabilidade no campo da bioestratí grafia. As gerações cristalinas formadas sobre as pare des celulares, durante a permineralização, refletem as condições diagenéticas da bacia de deposição; os carac teres anatômicos de maior realce, no plano lenhoso dos espécimes, refletem as condições ambientais da bacia, durante o tempo de vida da planta. Foram investigadas amostras representativas desde as oriundas das camadas Capivari às procedentes da Formação Estrada Nova, sob o prisma da tafonomia. De maneira geral as texturas cris talinas presentes complementaram as informações disponi veis sobre o ambiente de sedimentação das respectivas formações. As averiguações sobre a anatomia ecológica confirmam, de modo razoável, as idéias existentes sobre - ambiente deposicional da bacia durante os ciclos ques tionados. Em caso de contradições entre as correspondên cias aventadas é possivel admitir o retrabalhamento e o transporte do espécime, portanto, sua exclusão das ava liações.

Quanto às conclusões bioestratigráficas observa-se, "a priori", correlações sugestivas entre as associações lig nitafofloristicas das Formações Irati (Brasil), Barakar (fndia) e White Band (SW Africano); de modo incompleto, por falta de estudos estatísticos do lenho, entre as Formações Estrada Nova (Brasil), Raniganj (fndia) e, pe lo menos parcialmente, Ecca (SW Africano).

Com respeito aos estudos anatômicos também se fez a re formulação dos métodos de investigação. Esta apoia-se em resultados muitas vezes inabordados, ou esquecidos, de anatomistas mais antigos como VAN TIEGHEM (1872), CHAU VEAU (1911), entre outros, cujos conceitos, no que toca ao estelo das plantas fósseis, nortearam de maneira fun damental as determinações ora discutidas. Dessa aborda gem resultou a revisão dos estudos existentes sobre lig nispécimes permianos da Bacia do Paraná e gondvânicos em geral. Resultou, também, uma chave de determinação a qual congregou os morfogêneros, por grupos, de acordo com as feições de maior destaque presentes no estelo. A apreciação e a crítica concernentes aos morfogêneros dos respectivos grupos compreendem, na verdade, o desenvol vimento metodológico pelo qual se orientou nas determi nações sistemáticas.

Da presente revisão resultou a proposição de vários no vos taxa. Da Formação Rio Bonito foram descritos os no vos morfogêneros Schopficaulia nov. gen., Catarinopitys nov. gen. e Solidoxylon nov. gen.. Com respeito à For 
.26 .

mação Irati foram reconhecidos Kraeuselpitys nov. gen., Paulistoxylon nov. gen., Paranaseptoxylon, nov. gen., Atlanticoxylon nov. gen. e Petalopitys nov. gen.. As demais formas descritas compreendem espécies novas de morfogêneros conhecidos em publicações. Absteve-se de descrever amostras concernentes a espécies já conheci das dos respectivos morfogêneros, a não ser nos casos em que se tornou útil a sua inclusão, para efeito de emen das ou de melhores esclarecimentos quanto à anatomia.

1983

CANDIA, Maria Angela Fornoni

Petrologia dos complexos máfico-ultramáficos de Mangabal I e Man gabal II, Sanclerlândia, Goiás. 18 de setembro. $400 p$.

\section{Orientador: Vicente Antonio Vitório Girardi}

Resumo: 0s complexos de Mangabal I e Mangabal II constituem dois pequenos corpos máfico-ultramáficos diferenciados, or $\underline{i}$ ginados da cristalização fracionada de magma basáltico toleítico a baixa pressão, em câmaras magmáticas indivi duais, que se posicionaram num determinado nivel de um substrato siálico, representado, na área, por rochas gnaissicas e calcossilicatadas, atribuidas ao Complexo Basal Goiano.

Embora tectonicamente deformados e parcialmente recris talizados, os complexos preservam feições ígneas reli quiares correlacionáveis às descritas em complexos ígneos estratiformes.

Em função das feições ígneas presentes, e dentro do mo delo existente para complexos ígneos estratiformes, re constituiu-se o seguinte empilhamento estratigráfico or $\underline{\underline{i}}$ ginal:

a) em Mangabal I, a seqüência basal é constituída pelos olivina-cromo espinélio cumulatos (peridotitos feldspá ticos), à qual se segue os olivina-plagioclásio cumula tos (olivina gabronoritos), sobrepostos aos quais ocor rem os piroxênio-plagioclásio cumulatos (gabronoritos); b) em Mangabal II, a seqüência basal é representada pe la alternância de dois tipos de cumulatos ultramáficos, os olivina-cromo espinélio cumulatos(harzburgitos felds páticos), predominantes, e os bronzita cumulatos (bron zititos feldspáticos); a seqüência intermediária é re presentada pelos olivina-plagioclásio cumulatos (olivi na gabronoritos) e a seqüência superior,pelos piroxênioplagioclásio cumulatos (gabronoritos).

A olivina varia de $\mathrm{Fo}_{83}$ a $\mathrm{Fo}_{77}$ nos cumulatos ultramáf cos, alcançando composições de $\mathrm{Fo}$, nos olivina gabronō ritos. Os ortopiroxênios apresentam composições no cam po das bronzitas nos cumulatos ultramáficos, estendeñ 
do-se até o campo do hiperstênio nos gabronitos. 0 pla gioclásio apresenta composições em torno de $A_{64}$ nos cú mulatos ultramáficos, alcançando teores de $A n_{56} 64$ nos gá bronoritos. O clinopiroxênio situa-se no campo das au gitas, mostrando "trend" de enriquecimento em ferro, dos cumulatos ultramáficos para os máficos.

Os processos tectônicos subseqüentes são responsáveis pela atual configuração geológica dos complexos, que se apresentam deformados, com seqüências litológicas deslo cadas e falhadas. Em Mangabal I, as deformações tectôo nicas levaram à inversão da seqüência estratigráfica or $\underline{i}$ ginal.

Após a atuação dos processos tectônicos, seguiram-se os reequilibrios mineralógicos responsáveis pela recrista lização das rochas dos complexos, originando meta peri dotitos (coroniticos, a espinélio e clorita), meta harzz burgitos (coroníticos, a espinélio e a clorita), meta bronzititos, meta olivina gabronoritos (coroniticos e a espinélio), meta gabronoritos, bronzitas xistos e anto filita xistos.

Tais reequilibrios ocorreram em condições metamórficas de alto grau, a temperaturas da ordem de $700-780^{\circ} \mathrm{C}$ e a pressões mínimas da ordem de 6,0 a $6,5 \mathrm{kbar}$.

0 estudo do comportamento da fase fluida, fundamentado principalmente na análise de inclusões fluidas, permitiu estabelecer um modelo através do qual se explica a coe xistência de paragênese mais hidratadas, em razão da influência da fase fluida, mais rica em $\mathrm{H}_{2} \mathrm{O}$, ao lado de associações coroníticas e de associações ígneas reliquia res, causadas pela existência de uma fase fluida mais rica em $\mathrm{CO}_{2}$.

Abstract: The Mangabal I and Mangabal II complexes comprise two mafic-ultramafic differentiated bodies, originated in separate chambers by processes of low pressure fractional crystallization of a tholeiitic basaltic magma. They intruded a definite level of the sialic basement, represented in the area by gneissic and calc-silicate rocks, interpreted as belonging to the Goiás Basal Complex.

Although tectonically deformed and partially recrystallized, the complexes still preserve relict igneous features, similar to those described for stratiform igneous complexes. In conformity with such features and according to the existing models for igneous stratiform complexes, the original stratigraphic sequence can be reconstructed as follows:

a) in Mangabal I, the basal sequence is represented by olivine-chrome spinel cumulates (feldspar peridotites), followed by a sequence of olivine-plagioclase cumulates (olivine gabbronorites) above which are found pyroxene- 
plagioclase cumulates (gabbronorites);

b) in Mangabal II, the basal sequence is represented by two alternating ultramafic cumulates: (a) predominant olivine-chrome spinel cumulates (feldspatic harzburgites) and (b) subordinate bronzite cumulates (feldspatic bronzitites). An intermediate sequence is represented by the olivine-plagioclase cumulates(olivine gabbronorites) while the upper sequence is represented by pyroxeneplagioclase cumulates (gabbronorites).

Olivine varies from $\mathrm{Fo}_{83}$ to $\mathrm{Fo}_{77}$ in the ultramafic cumulates, reaching compositions of Fo in olivine gabbronorites. Orthopyroxene has bronzite composition in ultramafic cumulates, but becomes hypersthene in gabbronorites. Plagioclase has composition of calcic labradorite (An ${ }_{64}$ ) in the ultramafic cumulates, being as sodic as $A n_{56} i^{6}{ }^{4}$ the gabbronorites. The composition of clinopyroxene plots in the augite field, with an ironenrichment trend from ultramafic to mafic cumulates.

Subsequent tectonic processes are responsable for the present geologic configuration of the complexes, as shown by their deformed bodies, and faulted dislocated litologic sequence. At Mangabel I, the tectonic deformations led to the inversion of the original stratigraphic sequence. After the tectonic episode, mineralogical re-equilibrations caused the recrystallization of the mafic-ultramafic suite, originating metaperidotites(coronitic-, spinel-, and chloritic-); meta harzburgites(coronitic-,spinel-, and chloritic-); meta bronzitites, meta olivine gabbronorites (coronitic-, spinel-); meta gabbronorites, bronzite schists and anthophyllite schists.

These re-equilibrations occured at high grade metamorphic conditions, at temperatures of $700-780^{\circ} \mathrm{C}$, and at minimum pressures of $6,0-6,5$ kbar.

The study of the fluid phase composition, based mainly on fluid inclusion analysis, led to the establishment of a model which explains the coexistece of a more hidrated paragenesis, originated due to the influence of an $\mathrm{H}_{2} \mathrm{O}$-rich fluid phase, with coronitic and relict igneous associations, which are due to a $\mathrm{CO}_{2}-\mathrm{rich}$ fluid phase.

COIMBRA, Armando Márcio

Estudo sedimentológico e geoquímico do permo-triássico da Bacia do Maranhão. 18 de novembro. 259p. (2v.) Orientador: Setembrino Petri

Resumo: A Bacia do Maranhão, também chamada Bacia do Paranaíba ou Meio Norte, ocupa uma área de aproximadamente 600.000 $\mathrm{km}^{2}$ e abrange quase toda superfície dos Estados do Piauí e Maranhão e parte dos Estados de Goiás e Ceará. É es sencialmente uma bacia paleozóica, cujos sedimentos atinn gem espessura máxima de 3.000 metros, dos quais 2.500 
metros correspondem a sedimentos paleozóicos.

o Permo-Triássico desta Bacia, objeto de estudo deste trabalho, é representado pelas Formações Pedra de Fogo, Motuca e Sambaíba.

0 estudo integrado de diferentes critérios sedimentológi cos e geoquímicos (análise granulométrica, conteúdo mi neralógico das frações leve, pesada e argila,estudo geo químico e isotópico, análise petrográfica e determinação de paleocorrentes deposicionais) propiciou, além da ca racterização das unidades acima citadas, a identificação dos ambientes geradores destas rochas e ainda uma análi se do comportamento tectônico da Bacia nesta época.

A sedimentação inicia-se sob condições continentais ( $f$ lú vio-lacustre e eólica) e marinha epicontinental sob con dições de aridez climática durante a deposição da Forma ção Pedra de Fogo. A regressão do mar permiano e aumeñ to da aridez climática levam à deposição dos "red beds" da Formação Motuca, onde as intercalações de evaporitos são respostas aos mares interiores remanescentes.

No Triássico, sob condições nitidamente continentais ári das, ocorre a deposição dos arenitos eólicos das antigas dunas do deserto Sambaíba, sob influência de paleoventos oriundos de leste.

Associado a esta evolução, temos o aparecimento da fei ção tectônica positiva, definida neste trabalho e chamá da de Arqueamento de Alto Parnaíba. Tal arqueamento, inexistente antes do Permiano, tem, neste periodo, in fluência discreta na sedimentação da Formação Pedra dé Fogo, aparecendo como área menos negativa, separando as fácies de origem continental das de origem marinha lito rânea.

Durante a sedimentação da Formação Motuca, esta feição adquire caráter nitidamente positivo, limitando a depo sição desta unidade apenas no setor norte da Bacia. É ta feição positiva, adquirindo característica de sela, influiu no padrão regional dos paleoventos triássicos, formadores das areias da Formação Sambaíba.

Abstract: The Maranhão Basin, also known as the Parnaíba or Meio Norte Basin, occupies an area of approximately 600,000 $\mathrm{km}^{2}$, covering the States of Piaui and Maranhão almost entirely and parts of the States of Goiás and Ceará as well. It is essentially a Paleozoic basin with a maximum thickness of $3,000 \mathrm{~m}$, of which 2,500 m represent Paleozoic strata.

The Permo-Triassic of this basin, the object of this thesis, is represented by the Pedra de Fugo, Motuca, and Sambaíba Formations. The integrated study of sedimentologic and geochemical criteria (grain-size analysis; mineral content of the light, heavy, and clayey fractions; petrographic analysis; and paleocurrent determinations) 
have permitted not only the characterization of these formations and their depositional environnents but also the analysis of the tectonic behaviour of the basin during this time.

Sedimentation of the Pedra de Fogo Formation began under continental (fluvial - lacustrine and eolian) and epicontinental marine conditions within an arid climate. The withdrawal of the Permian sea and the increased aridity of the climate led to the deposition of the redbeds and intercalated evaporites (deposited from the waning inland seas) of the Motuca Formation.

In the Triassic, eolian arenites of the Sambaiba Formation were laid down as desert dunes under distinctly arid, continental conditions by paleowinds coming from the east.

Associated with this geological evolution, a positive tectonic feature appeared in the Permian which is herein defined and denominated as the Alto Parnaiba Arch. This arch exerted a mild influence upon sedimentation of the Pedra de Fogo Formation, separating the continental facies from the shallow marine facies. During the sedimentation of the Motuca Formation, this feature acquired a distinctly positive character, thereby limiting deposition of this unit to the northern portion of the basin and, during the Triassic, influencing the regional pattern of the paleowinds responsible for depositing the Sambaiba Formation.

KIHARA, Yushiro

o estudo mineralógico das cinzas volantes brasileiras: origem, características e qualidade. 19 de outubro. 223p.

Orientador: José Moacyr Vianna Coutinho

Resumo: As cinzas volantes são resíduos fundamentalmente silicoaluminosos, finamente divididos, provenientes da combus tão do carvão mineral pulverizado, utilizado em usinas termelétricas. São considerados materiais pozolânicos, à semelhança das cinzas vulcânicas ácidas, por apresen tarem capacidade de reação com a cal, em presença de água, originando a formação de compostos novos com pró priedades aglomerantes.

Estudaram-se 31 amostras de cinzas volantes das cinco principais termelétricas brasileiras movidas a carvão mineral, envolvendo o emprego de diversas técnicas ana líticas como análises químicas por gravimetria, comple xometria e fotometria de chamas, difratometria de raios $x$, análise termodiferencial, análise termogravimétrica, microscopia de luz transmitida e refletida, microssonda eletrônica e microscopia eletrônica de varredura e trans missão.

As cinzas brasileiras apresentam composição sillico-alu 
minosa com constituição secundária de ferro, cálcio, mag nésio e álcalis. Componentes como $\mathrm{TiO}_{2}, \mathrm{P}_{2} \mathrm{O}_{5}, \mathrm{Mn}_{2} \mathrm{O}_{3}$, $\mathrm{SrO}_{2}, \mathrm{~V}_{2} \mathrm{O}_{5}, \mathrm{Li}_{2} \mathrm{O}$, terras raras e outros estâno presentes na forma de trạços. O padrão de distribuição dos ele mentos químicos mais comuns ( $\mathrm{Si}, \mathrm{Al}, \mathrm{Fe}, \mathrm{Ca}, \mathrm{K}$ e Ti), observados por microssonda eletrônica nas cinzas das três principais termelétricas: Jorge Lacerda (SC), Char queadas (RS) e Presidente Médici (RS), apresentam seme lhanças entre si, com alguns grãos podendo apresentar concentrações maiores de um ou mais elementos.

As cinzas volantes das diferentes termelétricas brasi leiras são constituídas mineralogicamente por uma fasé vitrea principal, de natureza silico-aluminosa, e secun dariamente, por mulita, quartzo, hematita e magnetita. Associada aos grãos de cinzas é comum a ocorrência de carbono amorfo. Apresentam composições mineralógicas e feições morfológicas semelhantes, diferindo na proporção de seus constituintes e na freqüência das distintas fei ções morfológicas e microestruturais.

A formação da fase vítrea sílico-aluminosa está relacio nada à freqüência de argilominerais presentes e às con dições de combustão das partículas de carvão. A fase ví trea é o componente principal dos grãos não opacos dé formas arredondadas de aspecto esponjoso e esféricas. As cinzas da termelétrica de Jorge Lacerda são as que apresentam o mạior conteúdo de fase vitreae a maior fre qüência de esferólitos vítreos.

A mulita origina-se, principalmente, da caulinita por reações de mulitização durante a combustão do carvão e encontra-se sob a forma de inclusões na fase vítrea. Ocorre com freqüência nas cinzas das termelétricas de Jorge Lacerda (SC). São Jerônimo (RS), Charqueadas(RS) e Presidente Médici (RS). Nas cinzas da termelétrica de Figueiras (PR) foi detectada em baixas proporçбes, com teores menores que $5 \%$.

0 quartzo tem sua freqüência diminuída na cinza, em fun ção da temperatura de calcinação e finura do carvão, par ticipando na formação da fase vítrea e transformando-se parcialmente em cristobalita, em condições particulares de alta temperatura. Ocorre como grãos irregulares in dividualizados associados a particulas carbonosas e como inclusões na fase vitrea. Os teores mais altos de quart zo foram determinados nas cinzas das termelétricas de Presidente Médici (RS) e Charqueadas (RS).

A hematita e magnetita ocorrem com baixa freqüência em todas as cinzas estudadas provêm da decomposição e oxi dação de pirita, marcassita e pirrotita dos carvões. Os teores mais altos foram observados nas cinzas das terme létricas de Figueiras (PR) e São Jerônimo (RS).

A composição química, conteúdo de carbono, finura, mine ralogia e caracteristicas microestruturais e morfológ $\underline{\underline{i}}$ 
cas dos grãos de cinzas volantes são condicionados pelas características do carvão mineral utilizado, pelas condi ções de combustão e pelo sistema de coleta, constituin do parâmetros que influem no comportamento das cinzas vo lantes como materiais pozolânicos. A avaliação poten cial da qualidade das cinzas, fundamentada nesses parâa metros, mostra que as cinzas volantes da termelétrica Jorge Lacerda são as que apresentam as melhores caracte rísticas para o desenvolvimento das propriedades pozolâa nicas. Despontam, a seguir, as cinzas das termelétricas de Presidente Médici e Charqueadas. Por outro lado, as cinzas das termelétricas de Figueiras e de São Jerônimo apresentam-se potencialmente desfavoráveis, com caracte rísticas inadequadas para uso como pozolanas.

A aplicação dos conhecimentos e procedimentos de inves tigação da Mineralogia, no estudo das cinzas volantes brasileiras, concomitantemente ao estudo de modificações mineralógicas das fases presentes no material de partí da (carvão mineral), constituem condições necessárias e primordiais a uma melhor compreensão dos processos de formação, caracterização e avaliação da qualidade das cinzas como material pozolânico.

Abstract: Fly ashes are fine-grained silica-aluminous residues produced by the burning of pulverized mineral coal in thermoelectric plants. Like acid volcanic ashes, fly are regarded as pozzolanic materials as they react with lime in the presence of water to give rise to new binder compounds.

Thirty-one fly ash samples from the five main Brazilian coal-powered thermolectric plants were subjected to gravimetric chemical analysis, complexometry, flame photometry, X-ray diffractometry, thermodifferential and thermogravimetric analysis, transmitted and reflected light microscopy, electron microprobe analysis and transmited and scanning electron microscopy.

Brazilian fly ashes are essentially silica-aluminous in composition with lesser amounts of $\mathrm{Fe}, \mathrm{Ca}, \mathrm{Mg}$ and alkalies. Furthermore, they contain Ti, P, Mn, Sr, V, Li as trace elements. Similar distribution patterns of common elements ( $\mathrm{Si}, \mathrm{Al}, \mathrm{Fe}, \mathrm{Ca}, \mathrm{K}$ and $\mathrm{Ti}$ ) were observed by microprobe analysis in ashes from the three main power plants: Jorge Lacerda (SC), Charqueadas (RS) and Presi dente Médici (RS); however some grains show higher concentrations of one or more of these elements.

Mineralogically, the analysed ashes are made up principally, of a vitreous silica-aluminous phase accompanied by lesser mullite, quartz, hematite, magnetite and amorphous carbon. They exhibit homogeneous morphologic and mineralogic features, differing only in the proportion of their constituents and in the frequency of distinct features. 
The development of Si-Al glass is conditioned by the amount of clay minerals in the coal particles as well as by the attendant burning conditions. This vitreous phase is the main component of the rounded, "spongy" and spherical, non-opaque granules. The ashes at the Jorge Lacerda plant show the highest content of both the vitreous phase and glass spherulites.

Mullite occurs as inclusions in the glasses and is produced mainly from kaolinite by way of "mullitization" reactions which take place during the coal burning. It is a commonly occuring phase in the Jorge Lacerda, São Jerôni mo, Charqueadas and Presidente Médici plants: it has been detected only in minor quantities (less than 5\%) in ashes from the Figueiras plant.

The amount of quartz in the ashes diminishes with higher calcination temperatures and with coal fineness. Quartz takes part in the formation of the vitreous phase and at higher temperatures partially recrystallizes as cristobalite, it occurs as irregular grains included in glass or associated with carbon particles. The largest amounts of quartz were detected in ashes from the Pre sidente Medice and Charqueadas plants.

Hematite and magnetite were found in small amounts in all studied ashes. They are obtained from the decomposition and oxidation of pyrite, marcasite and pyrrhotite.

Chemical and mineralogical composition, carbon content, ard granularity as well as microstructural and morphological features of fly ash particles depend on the qualities of the mineral coal, burning conditions and the system used for their collections. Together, these constitute parameters which affect the behaviour of fly ashes as pozzolanic materials. An evaluation of the potential qualities of these ashes using these parameters indicates that the best ashes are those from Jorge Lacerda plant followed by those from the Presidente Médici and Char queadas ashes. On the other hand, the Figueiras and Săo Jerônimo ashes are poorly suited for use as pozzolanic material.

Application of mineralogical knowledge and investigation procedures in the study of Brazilian fly ashes, together with the study of the mineral phases obtained from the starting substance (mineral coal), is essential for a better understanding of the origin of ashes as well as for their technological appraisal as a pozolanic material.

MACIEL FILHO, Carlos Lej.te

Estudo do processo geoquímico de obstrução de filtro de barrą gens. 01 de junho. $136 \mathrm{p}$.

Orientador: Sérgio Estanislau do Amaral

Resumo: Esta tese apresenta o desenvolvimento dos estudos para 
explicar o processo de cimentação de filtros de barra gens com a conseqüente diminuição de sua permeabilidade. Os casos que estariam preocupando o meio geotécnico e que motivaram este estudo são principalmente o da barra gem do Rio Grande, em São Paulo capital,e o da barragem de Xavantes, no Rio Paranapanema.

As conclusões estão baseadas no tripé: revisão da teo ria e publicações específicas; levantamentos de campo; experiências de laboratório. Para estas, foram desen volvidos métodos e aparelhos próprios chegando-se a en saios que permitiriam: primeiro, medir com aproximaçå - volume de ar contido nos poros de uma areia sob fluxo não saturado; segundo, verificar a absorção de oxigênio pela água sob fluxo não saturado e comprovar uma dimí nuição dessa absorção com o prolongamento do ensaio; terceiro, verificar a deposição de hidróxido férrico na franja capilar e zona aerada de uma areia sob fluxo apro ximadamente horizontal após passar por camada de argila; quarto, verificar a mesma deposição em areia sob capa de argila e sob fluxo, de cima para baixo, não saturado. Em todos eles a água usada era deaerada e nos dois últí mos continha bicarbonato ferroso. Preliminarmente desen volveram-se ensaios que permitiram controlar a variaçāo da permeabilidade a longo prazo, eliminando-se o desen volvimento de seres vivos e evitando um rearranjo dos grãos de areia, pela aplicação de baixos gradientes.

As informações bibliográficas e os levantamentos de cam po indicam que a principal substância cimentante é o hị dróxido férrico.

o processo de cimentação é dividido em duas fases: a primeira é a de redução e solubilização do ferro com o comseqüente transporte, na forma de bicarbonato ferroso, através do maciço de terra, o qual é também o principal fornecedor daquele elemento, até o filtro; a segunda é a de oxidação e precipitação desse ferro no filtro.

A primeira fase encontra uma explicação fácil no ambien te redutor que se forma no fundo de um lago, o qual é representado pelo reservatório de barragem. Nesta fá se, as bactérias prestam uma importante contribuição. É se ambiente está descrito na bibliografia especializada e foi confirmado pelos levantamentos de campo.

A segunda fase reveste-se de aspectos mais complexos e de maior interesse, pois é possivel de ser evitada, enquanto a primeira é praticamente incontrolável.

A oxidação é provocada basicamente pelo oxigênio do ar absorvido pela água, podendo ser auxiliada ou não por se res vivos. Por isso, as condições de oxidação prendemse à aeração do filtro. Esta pode ocorrer na franja ca pilar ou nas partes aeradas acima do nível freático, sé o fluxo for aproximadamente horizontal, ou também em to do espaço do filtro, se o fluxo for essencialmente ve $\underline{\underline{r}}$ 
tical, de cima para baixo. Esta situação ocorre com fil tros horizontais ou inclinados para montante.

Estas condições inicialmente oxidantes podem, com o tem po, tornar-se redutoras, face à absorção seletiva do ar pela água, isto é, pelo consumo de oxigênio e permanên cia de nitrogênio. O próprio tubo de drenagem pode, no entanto, ser um caminho para o ar rico em oxigênio, como aconteceu na barragem de Rio Grande.

As soluções apontadas destinam-se a evitar a entrada de ar nos tubos de drenagem.

Chama-se a atenção, ainda, sobre as possibilidades de melhor aproveitamento da capacidade de aeração de um meio poroso sob fluxo não saturado.

Abstract: The precipitation of iron hydroxide in a filter dam decreases its permeability and is a process that can be divided into two steps: the first one is the reduction, solubilization and transportation of iron through the clay core; the second one is the oxidation and precipitation of this chemical substance.

The precipitation of iron is caused, basically, by the free oxygen of air absorbed by water. The filter aeration can occur in the capillary fringe or in the part above the phreatic level if the flow is essentially vertical, that is, from top to bottom. The latter situation can occur in horizontal or inclined upstream filters. States that are oxidant to begin with time, can become a reducing state through consumption of the dissolved oxygen in water and remaining nitrogen. However, the tubes of drainage may be a way for air rich in oxygen.

The developed method in the laboratory allowed the volume of air in the pores of sand under non-saturated flow to be measured, and to check the absorption of oxygen by water, and to confirm both the deposition of iron hydroxide in the capillary fringe and in the aerated zone of sand under nearly horizontal flow, and in sand covered by clay with a top to bottom non-saturated flow. The used water was non aerated and with iron bicarbonate, in the latter situation.

Field work confirmed anticipated conditions in the literature, and contributed to explain the phenomenum. The Rio Grande dam, located in São Paulo, Brazil, is a good case in point.

MADUREIRA FILHO, José Barbosa de

Determinação física da composiçao molecular de granadas. 27 de outubro. $181 \mathrm{p}$.

Orientador: William Gerson Rolim de Camargo

Resumo: A determinação molecular pelo método físico é uma técni ca indireta de análise da composição química de minerais 
.36 .

que compõem séries de soluções sólidas. O grupo minera lógico das granadas, com seus termos puros: almandina (Al), andradita (An), espessartita (Es), grossulária(Gr) e Piropo ( $P i)$, tiveram, neste trabalho, a determinação da composição molecular com auxilio deste método físico indireto.

As propriedades físicas utilizadas foram: indice de re fração $(n)$, diferença entre as reflexões de Bragg mais intensas do quartzo e da granada $\Delta d(d 10 \overline{1} 1$ Q - d 420 G) e a densidade relativa (D). As propriedades $n$ e $\Delta d$, graças a suas características intrínsecas e ao próprio método de determinação, merecem maior confiança nos seus valores, do que aqueles referentes à densidade relativa. Equações matemáticas (dez), resultantes da associação, três a três, dos cinco termos puros das granadas são apresentadas neste trabalho; sua finalidade é reconhe cer, através dos valores das propriedades físicas, o nú mero de componentes moleculares.

São também apresentados trinta diagramas triangulares, quinze quaternários e três quinários, produto das asso ciações três a três, quatro a quatro e da associação dos cinco termos puros considerados para as granadas. Todos os diagramas são bidimensionais e se prestam para o cál culo das quantidades moleculares que ocorrem nas grana das. Os diagramas quaternários recebem, no desenvolvi mento deste trabalho, um novo tipo de tratamento e os diagramas de cinco componentes são apresentados pela pri meira vez.

A avaliação do método físico foi comprovada em vinte e oito amostras de composições conhecidas; entre essas, existem granadas com composição molecular teórica, gra nadas analisadas por via úmida e granadas analisadas por microssonda eletrônica.

Abstract: The physical determination of molecular composition of solid solutions is an indirect method of chemical analyses of minerals, where garnets is should be regarded as an example; a garnet may be a solid solution of almandine $(A l)$, andradite $(A n)$, spessartine (Sp), grossular (Gr) and pyrope (Py).

The investigated physical properties are: refraction index $(n)$, interplanar spacement difference $\Delta d(d 10 \overline{1} Q$ d 420G), and specific gravity (D), from which, $n$ and $\Delta d$ are most reliable ones.

Then mathematic equations, results from the association of the five garnet end members are presented in this paper, whose aim the recognition, through the physical values, of the number of end members,presented in the garnet composition.

30 3-component diagrams, 15 4-component diagrams and 3 5-component diagrams are presented as a result of 
association of the garnet end members. The above diagrams are two dimensional diagrams, which could be used to determine the molecular constitution of garnets.

The 4-component equilateral diagrams received here, distinctive approach and the 5 -component diagrams is for the first time introduced in this paper.

The physical method is checked in 28 garnet samples of known composition: garnets of theoretial composition, garnets analysed by conventionals chemical methods, and garnets analysed in the electron microprobe.

\section{PARADELA, Waldir Renato}

Discriminação de unidades litológicas no Baixo Vale do Rio Curaçá (Bahia), através de realces por processamento digital de dados MSS-Landsat 3. 07 de dezembro. 249p.

Orientador: Gilberto Amaral

Resumo: Informações espectrais e multisazonais detectadas pelo MSS-Landsat 3, realçadas por técnicas de tratamento por computador, foram avaliadas no contexto de discriminar unidades litológicas de uma região tropical semi-árida, no Nordeste do Brasil.

A área escolhida (Baixo Vale do Rio Curuçá, Estado da Bahia) é constituída por rochas metamórficas arqueanas/ proterozóicas, de alto a baixo grau e é parte da impor tante província cuprífera do Vale do Curaçá, distando $100 \mathrm{~km}$ ao norte da Mina de Caraíba.

A vegetação é representada por espécies de "caatinga", típica do semi-árido brasileiro, com variada densidade de recobrimento e marcada sazonalidade. A densidade de afloramentos na área é relativamente baixa.

As técnicas aplicadas, incluindo (1) Ampliação Linear de Contraste, (2) Composições Coloridas Contrastadas, (3) Divisões de Canais, (4) Componentes Principais, possibi litaram enfatizar diferenças sutis de reflectância es pectral da superfície, indicativas de um controle geobo tânico dado por variações nas densidades de cobertura vegetal e de mudanças composicionais nos solos residuais, bem correlacionadas com as variações litológicas do subs trato. Os padrões tonais extraídos, corresponderam ex cepcionalmente bem com as unidades litológicas,cartogra fadas por mapeamentos geológicos convencionais, na esca la $1: 50.000$ e forneceram, adicionalmente, novas contri buições ao conhecimento da área.

As medidas espectrais "in situ" das condições superfi ciais das unidades e em laboratório, de amostras de so lo, mostraram-se compatíveis com os dados registrados no MSS-Landsat e forneceram subsídios para o entendimento das causas das variações espectrais registradas.

Uma análise do desempenho visual dos vários produtos realçados na discriminação litológica, foi também desen 
.38 .

volvida, utilizando-se de critérios de seleçoes de atrí butos espectrais.

A comparação visual do conteúdo de informação de signi ficado geológico, contido nos vários realces, mostrou que o produto híbrido (canais $4,5 / 7$ e 7 , associados às cores verde, azul e vermelha) e a composição colorida normal (canais 4, 5 e 7 e cores azul, verde e vermelha), apresentaram os melhores desempenhos, com informaçðes complementadas pelos realces por Componentes Principais. os produtos "ratios" foram os que apresentaram maiores ambiguidades nas discriminaçôes, com desempenhos infe riores aos Componentes Principais.

Os dados analisados da passagem da época seca, não foram por si só suficientes para exprimir as diferenças lito lógicas na área, sendo valiosa a contribuição da abordá gem multitemporal.

Espera-se que com os aperfeiçoamentos futuros nos senso res do Landsat 4 e com melhoramentos nas técnicas de tra tamento digital, a abordagem aqui realizada, possa ser, com sucesso, aplicada em regiões com outras condiçðes ambientais.

Abstract: Spectral and multispectral informations detected by computer enhanced Landsat - MSS 3, were evaluated within the context of lithological discriminations in a semiarid tropical region of the northeast of Brazil.

The chosen area (lower Valley of Curaçá River, State of Bahia), is made up of low to high grade Archean/Proterozoic metamorphic rocks, and constitutes part of the important copper province of the Curaçé Valley, located $100 \mathrm{~km}$ north of the Caraiba Copper Mine.

The vegetation is represented by the "caatinga",typical of the Brazilian semi-arid region and which has varying cover density and marked seasonality. The occurence of outcrops or exposed rocks is small.

The techniques used, including (1) linear contrast stretch, (2) contrast stretched colos composites, (3) band-ratioing and (4) Principal Components, make it possible to emphasize subtle differences in the spectral reflectance of the surface, good indicators of geobotanical controls given by variations in the vegetations cover and the changes in the residual soil compositions well correlated with the lithological variations of the substratum. The observed brightness and tonal patterns correspond exceptionally well to the lithological units mapped by conventional geological methods in the $1: 50.000$ scale and provided, additionally, new contributions to the geological understanding of the area.

The spectral measurements, collected in situ for the surface conditions of the units and in the laboratory for the soil samples, showed to be compatible with the 
data registered by the Landsat - MSS CCTS and provided subsidies to the understanding of the causes of the variations in the registered spectral data.

An analysis of the visual performance of the enhanced products for lithological discrimitations was performed utilizing criterion of spectral atributes selection (JM distance).

A visual comparison of the data expressing geological information obtained from the enhancements showed that the hybrid product (Bands $4,5 / 7$ and 7 associated to green, blue and red colors, respectivelly), and a standard color composition (Bands 4,5 and 7 associated to blue, green and red, respectivelly) had the best performance, with information being complemented by the Principal Componentes enhancements.

The band-ratio products were the ones presenting greater ambiguity in the discriminations, with a performance inferior to the Principal Componentes.

The analysis of the data from the dry season was not sufficient by itself in expressing the lithological differences, but the miltitemporal approach was of great value.

With the future sensor improvements in Landsat 4 and betterment of digital treatment techniques, it is expected that the approach utilized in this study can be applied with success in regions with other ambiental conditions.

SILVA, Rosa Beatriz Gouvêa da

Estudo hidroquímico e isotópico das águas subterrâneas no Aqüífe ro Botucatu no Estado de São Paulo. 20 de outubro. $133 p$. Orientador: Aldo da Cunha Rebouças

Resumo: Neste trabalḩ são utłjizadąs técnicas hidroquímicas e isotópicas ( ${ }^{18} \mathrm{O},{ }_{\mathrm{H}},{ }^{13} \mathrm{C}$ e $\left.{ }^{14} \mathrm{C}\right)$ para investigar os meca nismos da evolução da composição química, origem,idades aparentes e velocidades de circulação das águas subter râneas do aqüifero Botucatu do Estado de São Paulo. Os resultados obtidos mostram que estas águas são originá rias, principalmente, da infiltração das precipitaçðes na zona de afloramento do aqüífero, sendo sua evolução hidroquímica determinada pelas condições de confinamen to do aqüífero, pelas direções e sentidos do fluxo sub terrâneo e pelo tempo de residência das águas. Esses fá tores implicam em um aumento da temperatura e da salin dade das águas no sentido sudoeste, desde a zona afloran te até a região fortemente confinada do aqüifero. Nes te sentido, as águas recentes bicarbonatadas magnesianas e calco-magnesianas evoluem para bicarbonatadas cálcí cas, bicarbonatadas sódicas e cloro-sulfatadas sódicas, quando chegam a atingir idades da ordem de 30.000 anos. A permeabilidade média aparente calculada a partir dos 
.40 .

dados de ${ }^{14} \mathrm{C}$ e de gradiente hidráulico é cerca de $2,6 \times$ $18_{0}^{-5} \mathrm{~m} / \mathrm{s}$. ${ }^{A}$ variação dos teores dos isótopos estáveis síveis oscilações climáticas nas diferentes épocas de recarga dessas águas. Há 30.000 anos reinava um clima quente e úmido que, por influência do último período gla cial ocorrido no hemisfério norte, passa, entre 25.000 e 11.000 anos, a frio e seco, e, então, gradualmente, ad quire as caracteristicas atuais.

Abstract: The processes controlling chemical composition of groundwater, its origin and apparent age as well as the natural flow rate of the water in Botucatu aquifer in State of São Paulo, Brazil, have been investigated usigg
hydrochemical and environmental isotopic ( ${ }_{0},{ }_{\mathrm{H}},{ }_{\mathrm{C}}$ e ${ }^{~} c$ ) techniques. The main recharge process is assumed to be the infiltration of rain water in the aquifer outcrop area. The progressive confining condition with the increasing depth of the top of aquifer layer makes the groundwater temperature slowly greater. Moreover, the residence time increases the water salt content towards the natural flow direction (southwest). By this way, the recent megnesium and sodium bicarbonated waters changes first to sodium carbonated and then to sodium chloride-sulfated waters which are the oldest found out in the research area (around 30.000 years ago), The mean Darcy permeability estimated on basis of ${ }^{14} \mathrm{C}$ and hydraulic gradient data is $2,6_{8} \times 10_{2}^{-5} \mathrm{~m} / \mathrm{s}$. 13 Different amounts of stable isotopes ${ }^{18} \mathrm{C},{ }^{2} \mathrm{H}$ and ${ }^{13} \mathrm{C}$ of the groundwater had allowed to suppose that the warm and humid climate of 30.000 years ago has changed, between 25.000 and 11.000 years ago, to cold and dry, by influence of the last glacial period of the northern hemisphere and then, gradually, has acquired the characteristcs of nowadays climate of the region.

ALMEIDA FILHO, Raimundo

Sensoriamento remoto orbital aplicado à prospecção mineral nas províncias estaníferas de Goiás e Rondônia: uma contribuição me todológica. 12 de março. $171 \mathrm{p}$.

Orientador: Gilberto Amaral

Resumo: Discute-se neste trabalho uma linha metodológica de uti lização de dados de sensoriamento remoto orbital, comó ferramenta de auxilio a campanhas de prospecção mineral, exemplificada no estudo de corpos graníticos das Provín cias Estaniferas de Goiás e de Rondônia.

Inicialmente faz-se uma discussão do papel dos diversos 
parâmetros que interagem para compor o sinal gravado pe los sistemas sensores. São parâmetros fundamentais no processo de análise e interpretação de dados multiespec trais em geologia: as características fisiográficas da região; as características geológicas do "alvo" pesqui sado; o papel das variáveis sazonais (cobertura vegetal e condições de iluminação); as características do sís tema sensor (resoluções); e as técnicas de realce de ima gens digitais através do emprego de computadores. A ut $\underline{i}$ lização de imagens digitais/multiespectrais do sensor MSS-Landsat, levando em consideração todos os aspectos acima, permitiu a discriminação de áreas de ocorrências de fácies greisenizadas ("lato sensu") associadas a cor pos graniticos da Província Estanífera de Goiás, as quais são controles litológicos de mineralizações de $\mathrm{Sn}, \mathrm{W}, \mathrm{Nb}-\mathrm{Ta}, \mathrm{Li}, \mathrm{F}$, etc. O parâmetro básico que permi tiu a discriminação destas áreas através das imagens or bitais foi o comportamento espectral destes tipos lito lógicos e/ou de suas associações específicas de rochasolo-vegetação. Em Rondônia, dadas as características da região (profundo manto de intemperismo, coberturas se dimentares quaternárias e floresta tropical), não é pos sível a discriminação espectral de litotipos especifi cos. No entanto, mesmo sob essas condições, a imagem Landsat realçada por computador, mostrou os traços geo lógicos principais e a estruturação do maciço granítico estudado, feições estas não observadas através de foto grafias aéreas ou de imagens de Radar. Os resultados ob tidos em Goiás e em Rondônia mostram que utilização ade quada de imagens de sensoriamento remoto orbital pode contribuir de maneira efetiva na orientação a trabalhos de prospecção mineral, propiciando economias razoáveis de tempo e de recursos na etapa de levantamentos de cam po.

Abstract: This study presents a line of procedures for the utilization of orbital remote sensing data as supporting tools in mineral prospecting campaigns, exemplified here by studies in granitic bodies of the Tin Provinces of Goiás and Rondônia. Initially, a discussion is made on the role of several interacting parameters that compose the recorded signal in sensor systems. The fundamental parameters in the processes of analysis and interpretation of multispectral data in geology are: the physiographic characteristics of the region; the geological characteristics of the target investigated; the role of the seasonal variables (vegetation cover and illumination conditions); the characteristics of the sensor system (resolutions); and the use of computer enhancement techniques applied to digital images. Taking into consideration the above aspects, the utilization of Landsat multispectral/digital 
.42 .

images has allowed the discrimination of areas with occurences of greisenized facies ("lato sensu") associated with the granitic massifs in the Goiás Tin Province. The greisens are lithological controls of mineralizations in $\mathrm{Sn}, \mathrm{W}, \mathrm{Nb}-\mathrm{Ta}, \mathrm{Li}, \mathrm{F}$, and others. The basic parameter that allowed the discrimination of these areas in orbital images was the spectral behaviour of these lithological types and/or of their specific rock-soil-vegetation associations. In Rondônia, due to the particular characteristics of the region (deep weathering, Quaternary sedimentary cover, and tropical forest), a spectral discrimination of specific lithotypes is not possible. However, even under these adverse conditions, computer enhanced Landsat images showed the main geological and structural features of the studied granitic massif. These were not observed in aerial photography or Radar images. The results obtained in Goiás and Rondônia show that an adequate utilization of orbital remote sensing images can contribute for the orientation of field work, yielding reasonable saving in time and resources during mineral prospecting compaigns.

BATISTA, Job Jesus

Caracterização dos processos geológico-evolutivos pré-cambrianos na região de São Fidélis, norte do Estado do Rio de Janeiro. 07 de dezembro. 123p.

\section{Orientador: Marcos Aurélio Farias de Oliveira}

Resumo: Após vários anos de levantamento geológico básico na re gião do Estado do Rio de Janeiro, propôs-se o desenvol vimento de pesquisa mais detalhada, de cunho científico mais profundo, tendo em vista a variedade de interroga ções petrogenéticas que se levantavam dentro do panora ma geológico-evolutivo, configurado como de extrema com plexidade.

Além dos trabalhos iniciais de mapeamento geológico sis temático, na escala 1:50.000, foram implementados trabá lhos adicionais de campo em áreas selecionadas,petrogra fia de detalhe, estudos geocronológicos e abordagens geoquímicas.

As feições tectônicas, estruturais e texturais, bem co mo as evidências petrológicas e os padrões geocronológi cos e geoquímicos apresentados pelas rochas estudadas, permitem a caracterização dessa faixa comode típico cin turão móvel ("mobile belt") ensiálico. O relacionamento complexo entre os vários tipos litológicos é condiciona do pelo caráter policíclico da faixa estudada,onde ocor rem diversos processos (plutonismo, migmatização, metá morfismo, deformação, anatexis ou palingênese, etc.) em diferentes fases precambrianas, muito provavelmente sen do atribuída ao Arqueano a fase primordial geradora de rochas. 
Acredita-se que boa parte da crosta continental dessa região já estava formada desde o Arqueano, sendo de cons tituição siálica, havendo retrabalhamento por deformação cisalhante no Ciclo Transamazônico e por anatexis/palin gênese no Brasiliano.

Relacionado ao Arqueano ter-se-ia o embasamento plutôni co (Agrupamento I do Complexo Juiz de Fora), de afinida de tonalítica (enderbitos e gnaisses porfiroblásticos), representando crescimento crustal através de processos plutônicos, com "trend" de diferenciação predominantemen te de natureza calco-alcalina. Algumas indicaçoes tole ticas poderiam significar um certo caráter bimodal. A esse embasamento sobrepor-se-ia pilha supracrustal(Agr $\underline{u}$ pamento III - Complexo Paraíba), cujos produtos origi nais, depositados em tempos pré-Transamazônicos, seriam pelitos, psamo-pelitos, psamitos, margas, calcários, do lomitos, além da contribuição vulcânica.

Durante o Ciclo Transamazônico (Proterozóico Inferior) todo o conjunto arqueano (embasamento + supracrustais) seria intensamente afetado por movimentos cisalhantes, promovendo forte blastomilonitização e cataclase, com aparecimento da primeira fase de migmatização, de ca ráter sin-tectônico, onde duas entidades apresentam ex pressão cartografável (unidades São José de Ubá e Monté Verde - Agrupamento II do Complexo Juiz de Fora). No Ciclo Brasiliano (Proterozóico Superior) ocorre gene ralizada anatexis formando importantes massas granitó des e migmatitos a partir de produtos rochosos com vi vência crustal anterior, caracterizando as entidades do Complexo Serra dos órgãos. Também, neste ciclo, ocorre ram falhamentos transcorrentes em faixas reativadas.

Não negligenciável é a possibilidade de atuação de even to intermediário entre os ciclos Transamazônico e Brasi lianoa (Ciclo Uruaçuano), relacionado ao Proterozóico Médio ( $\pm 1.000 \mathrm{~m} . \mathrm{a}$.$) . Suportando esta hipótese existem$ algumas insinuações em resultados geocronológicos publi cados.

No Meso-cenozóico atuaram processos tracionais, respon sáveis pela quebra, fragmentação e separação do Gondwā na, aos quais se ligariam magmatismo básico (diques de diabásio), magmatismo alcalino e formação de bacias cos teiras.

A evolução cinemática do cinturão é largamente dominada por movimentos verticais, porém análise de zonas de cisa lhamento indicam movimentos transcorrentes.

Pelas descrições dos processos atuantes no Arqueano, Pro terozóico Inferior, Proterozóico Superior e Fanerozóico chega-se a uma postura não-uniformitarista em relação aos regimes tectônicos que afetaram esta porção da Pro víncia Mantiqueira, no norte fluminense, atribuindo-selhe rápido crescimento no Arqueano por fenômenos plutô 
.44 .

nicos; cisalhamento intenso no Proterozóico Inferior; predominância de eventos termais e reativações deforma cionais no Proterozóico Superior e processos tracionais no Fanerozóico. Desta maneira estabelecem-se grandes descontinuidades entre cada uma das eras geológicas.

Abstract: This work deals with a study of geological processes in the evolution of a part of the North Fluminense region, which belongs to a polycylic mobile belt.

Besides the systematic 1:50.000 scale geological mapping, additional field work was carried out followed by detailed petrography, geochronological studies and geochemistry. In accord with the description of the processes that occurred in the Archean, Lower and Upper Proterozoic and Phanerozoic, a non-uniformitarian view is adopted for the tectonic regimes that affected this part of the Mantiqueira Province. The overall picture can be envisaged as one of rapid growth by plutonic phenomena ascribed to the Archean, intense shearing during Lower Proterozoic, predominance of thermal events and reactivated deformation in the Upper Proterozoic, and tractional processes in the Phanerozoic. In this way, distinct and significant discontinuities can be established between each geological era.

BRANDT NETO, Max

0 Grupo Bauru na região Centro-Norte do Estado de São Paulo. 27 de abril. 167p. (2v.)

Orientador: Setembrino Petri

Resumo: Os sedimentos do Grupo Bauru na área centro norte do Es tado de São Paulo foram estudados por critérios sedimen tológicos de campo e de laboratório. No primeiro caso, procurou-se descrever a litologia e estruturas sedimen tares presentes nos sedimentos, visando a determinação dos paleoambientes deposicionais. Os estudos de labora tório envolveram aspectos texturais,mineralógicos e quí micos dos sedimentos, utilizando-se de análises granulo métricas, petrográficas, isotópicas, e ainda de difra ção de raios $x$ e microscopia eletrônica de varredura pa ra a determinação dos argilominerais.

o estudo estratigráfico do Grupo Bauru na área em pauta, aliado ao conhecimento de outras áreas da bacia Bauru, possibilitou a apresentação da seguinte coluna estratí gráfica: Formação Caiuá, Formação Santo Anastácio, For mação Adamantina, Formação Iporá, Formação Uberaba e For mação Marilia. Tal proposição promoveu a integração de todas as unidades que compõem o Grupo Bauru na sua ba cia de sedimentação, diferindo, portanto, daquelas pró posições de cunho mais localizado e válidas apenas para determinados setores da bacia. 
Na área em pauta, os sedimentos do Grupo Bauru são re presentados pelas Formações Adamantina e Marília, ev $\underline{i}$ denciando uma sedimentação continental. Estas formá ções, por sua vez, foram subdivididas em unidades infor $\underline{r}$ mais.

Sedimentos imaturos textural e mineralogicamente da Uni dade BM-1 - Formação Adamantina, sugerem sua origem a partir de rios anastomosados e leques aluviais. Lateral mente, em direção ao centro da bacia, esta unidade é cá racterizada por arenitos com melhor seleção, ricos em estruturas sedimentares (estratificações cruzadas), que se alternam com camadas silticas, indicativos de ambien te fluvial meandrante.

Fases climáticas secas, com chuvas intensas esporádicas, ocasionaram a deposição de arenitos mais argilosos, ma ciços, com abundante nódulos carbonáticos, constituindo bancos (Unidade BM-2 - Formação Adamantina). Este incre mento de condiçôes climáticas secas, coincide com a ocor rência de processos magmáticos na região, representados pelas lavas alcalinas analcimíticas da Formação Iporá.

Sucedem-se ao topo, arenitos mais grosseiros, imaturos, com intensa cimentação carbonática e a presença do argi lomineral paligorsquita. Formam bancos areníticos espes sos, característicos, correspondentes à Unidade BS-1 da Formação Marília (Fácies Ponte Alta). Estes arenitos são indicativos de deposição em clima semiárido, sob con dições de leques aluviais coalescentes.

o final da sedimentação da bacia Bauru na área estudada é representado pelos arenitos mais finos, argilosos e vermelhos da Unidade BS-2 da Formação Marília (Fácies Serra da Galga).

Abstract: The Bauru Group sediments in the central-north part the State of São Paulo were studied using field and laboratory sedimentological criteria. Lithologies and sedimentary structure were studied in the field,in order to determine the depositional paleoenvironments. The laboratory studies investigated textural, mineralogical and chemical aspects of the sediments. For this purpose,grain-size, petrographic and isotopic analyses were utilized. Clay minerals were determined by $X$-ray diffraction and scanning microscopy.

This stratigraphic study of the Bauru Group, together with knowledge of others areas of Bauru Basin, has permitted the presentation of the following stratigraphic column (from the base upwards): Caiuá Formation, Santo Anastácio Formation, Adamantina Formation, Iporá Formation, Uberaba Formation and Marilia Formation. This proposal integrates all units comprising the Bauru Basin, thus differing from other schemes valid only for restricted areas of basin. 
.46.

In the studied area the sediments of the Bauru Group represent continental sedimentation and may be separated into the Adamantina and Marilia Formation,each of which has been further subdivided into two informal units. The presence of texturally and mineralogically inmature sediments of the BM-1 Unit (Adamantina Formation)suggests its origin from braided rivers and alluvial fans. Laterally toward the center of the basin, this unit is characterized by well-sorted sandstones, rich in sedimentary structure (cross stratifications), intercalated with siltstone beds, which suggests a meandering fluvial environment.

The deposition of massive, argillaceous sandstones, rich in horizons of calciferous nodules characteristic of the BM-2 Unit (Adamantina Formation) took place under a dry climate with intense, sporadic rainfall. The progressive increase in dry climatic conditions coincided with magmatic processes in the regions, represented by the analcimitic alkaline lava of the Iporá Formation.

Above the BM-2 Unit, in the Marilia Formation, coarse, immature, calcite-cemented sandstones containing the clay mineral paligorskite form characteristic thick sandstone benches of the BS-1 Unit (Ponte Alta Facies). These sandstones are indicative of deposition in semiarid climate, under coalescent alluvial fan conditions.

The final sedimentation of the Bauru Basin in the studied area is represented by reddish, argillaceous fine sandstones of the BS-2 Unit of Marilia Formation (Serra da Galga Facies).

CARNEIRO, Celso Dal Ré

Análise estrutural do Grupo São Roque na faixa entre o Pico do Jaraguá e a Serra dos Cristais, SP. 21 de março. 152p.

Orientador: Yociteru Hasui

Resumo: Trabalhos de análise estrutural foram desenvolvidos nu ma faixa de cerca de $376 \mathrm{~km}^{2}$ situada entre o Pico do Já raguá (Município de São Paulo) e a Serra dos Cristais (Municipio de Jundiai), possibilitando reconstituir as fases de dobramento do Grupo São Roque no tocante às suas características de estilo, natureza das foliaçoes plano-axiais e vinculação com os fenômenos de metamorfís mo e magmatismo. Os padrões de deformação e metamorfís mo foram estabelecidos com base em estudos microestrutú rais.

$\mathrm{Na}$ área estudada a reconstrução estratigráfica do Grupo São Roque é limitada pela pobreza de dados de polarida de das camadas e a falta de clareza sobre a natureza das dobras da primeira fase de dobramento. No entanto, é possível reconhecer quatro seqüências litoestratigráfí cas gerais, ainda denominadas de modo informal, que com 
preendem, da base para o topo: 1) metapsamitos impuros, com intercalações de metaconglomerados polimíticos, me tavulcânicas (algumas delas descobertas no presente es tudo), filitos e quartzitos; 2) metapelitos, represen tados por filitos e xistos de diversos tipos, muitas vezes com intercalações de metarenitos. Este pacote tem passagem gradual para os outros dois; 3) metamargas e prováveis metatufos, representados por rochas cálcio-si licáticas e anfibolitos bandados, com níveis subordina dos de calcários e dolomitos; 4) metapsamitos rítmicos, compostos por metarenitos, metarcóseos e filitos interca lados, com níveis estreitos de metarenitos microcongló meráticos.

As rochas metamórficas da área foram generalizadamente afetadas por três fases de dobramento, que geraram pa drões de interferência observáveis nos afloramentos e em macroescala. A fase $F$, gerou clivagem ardosiana ou $x i \underline{s}$ tosidade em posição plano-axial a dobras fechadas a ce $\underline{\underline{r}}$ radas, sucedendo-se então o pico do metamorfismo regío nal, já em condições pós-cinemáticas. 0 metamorfismo nesta etapa permitiu a blastese de opacos, granada, es taurolita e sillimanita, cujas isógradas foram posterior mente deformadas durante $F_{2}$. Determinou-se a continui dade desse evento metamórfico principal, pelo menos, páa ra a estaurolita, até as etapas iniciais do segundo ep $\underline{i}$ sódio de dobramento, que formou uma persistente clivagem de crenulação, frequentemente do tipo zonal e microscó pica, em posição plano-axial a dobras fechadas a cerrá das. O metamorfismo que acompanhou esta fase é represen tado por bandamento diferenciado e alguma recristaliza ção de biotita ao redor de opacos. A terceira fase de dobramento, denominada $F_{3}$, criou clivagem de crenulação mais espaçada e não mais do tipo zonal, tão comum na fá se anterior. Esta fase gerou amplas dobras e ondulaçôs nas estruturas regionais e teve maior intensidade na parte sul da faixa estudada.

As manifestações granitóides foram reunidas em três gru pos. As de caráter pré-tectônico a $F$ são representadas pelos granitos de Francisco Morato e 2 ico-Tico, ao re dor dos quais são freqüentes os bolsões de pegmatitos gnaissificados e os veios pegmatiticos dobrados por $F$. Os batólitos de Cantareira e Itaqui, e os "stocks" de Itaim e Taipas são considerados do intervalo tardi-tec tônico em relação a $\mathrm{F}_{2}$ a sintectônico a $\mathrm{F}_{3}$. Os grani tos turmaliniferos de ${ }^{2}$ perus e pegmatitos associados re presentam manifestações pós-tectônicas, bem como as res tritas zonas de falhamento.

Abstract: Structural analysis of the São Roque Group in an area of $376 \mathrm{~km}^{2}$ between the Pico do Jaraguá (Municipality of 
São Paulo) and the Serra dos Cristais (Municipality of Jundiai) has permitted the reconstruction of three phases of folding as determined from characteristics of fold styles and the nature of axial-plane foliations. These phases of folding are linked to metamorphic and magmatic phenomena. Microstructural studies have shown the relationship between deformation and metamorphism.

In the studied area, stratigraphic reconstruction of the São Roque Group is limited by the paucity of data on stratigraphic younging and a lack of clarity as to the data on the first phase of folding. Nevertheless, it is possible to recognize four main lithostratigraphic units, informally designated (from apparent base upwards) as follows: 1) impure metapsammites, with intercalations of polymictic metaconglomerates, metavolcanics (some of with were descovered during this study), phyllites and quartzites; 2) metapelites, represented by phyllites and schists of several types, with many intercalations of metarenites. Unit 2 grades laterally and vertically into the following two units; 3 ) metamarls and probable metatuffs, represented by calc-silicate rocks, with subordinate limestones and dolomites; 4) rhythmic metapsammites, made up by alternating metarenites, metarkoses and phyllites, with narrow zones of microconglomeratic metarenites.

The metamorphic rocks of the area were affected by three phases of folding that generated interference patterns observable in both outcrops and maps. The $F$ phase was accompanied by the formation of axial-plane slaty cleavage or schistosity related to tight folds and followed by the regional metamorphic peak under postkinematic conditions. During this peak prophyroblasts of opaque minerals, garnet, staurolite and sillimanite developed. This main metamorphic event continued, at least for staurolite, into the beginning of the second folding episode. The $F$ phase generated a persistent crenulation cleavage, frequently both microscopic and of the zonal type, in axial-plane position of tight folds. Differentiated banding and some recrystallization of biotite around opaque minerals occurred during this phase. The third folding phase, $F_{3}$, created more spaced crenulation cleavage not of the zonal type so commom in the $F_{2}$ previous phase. The $F_{3}$ phase which was more intense in the southern part ${ }^{3}$ of the area, generated large folds and undulations in regional structures. Granitoid intrusions are subdivided into three groups. The bodies formed prior to $F$ tectonism are represented by the granites of Francisco Morato and Tico-Tico. Gnaissified pegmatites and folded pegmatitc veins are common in the regions surrounding these bodies. The Can tareira and Itaqui batholiths and the Itaim and Taipas 
stocks are considered as synchronous to the tarditectonic events of $F_{2}$ and the syntectonic events to $F_{3}$. The tourmaline-bearing granites of Perus and associated pegmatites correspond to post-tectonic intrusions and were followed by faulting in narrow zones.

CHIANG, Liu Chan

Análise estrutural de lineamentos em imagens de sensoriamento re moto: aplicação ao Estado do Rio de Janeiro. 20 de agosto. $157 p$.

\section{Orientador: Gilberto Amaral}

Resumo: A coleta de dados numa escala adequada ao tipo de fei ção geológica a ser analisada é o princípio básico da aplicação do sensoriamento remoto a estudos estruturais. A influência das várias formas de estruturas na geomorfo logia é de tal modo conspícua, que os estudos estrutú rais em escala regional têm na análise das feiçoes topó gráficas seu principal critério para a interpretaçăo de seus significados geológicos.

Entretanto, é necessário que se tenham os meios e os mé todos mais apropriados para que tais feições estruturais possam ser analisadas dentro do contexto de sua dimensão regional. O sensoriamento remoto a nível orbital é uma destas possibilidades e inclui as imagens Landsat como uma das principais opções para o estudo de alguns impor tantes aspectos acerca de certas feições estruturais. É óbvio que não se pode exigir que uma única ferramenta venha a satisfazer todas as expectativas num estudo de geologia estrutural. Quaisquer proposições de modelos estruturais ou deduções de maior alcance, como,por exem plo, sobre evolução tectônica, necessitarão forçosamen te da conjunção de outros niveis de informações ou t $\underline{i}$ pos de dados. Sem esta conjunção de informações as pró sições baseadas em modelos encontrados na literatura pó derão ser concebidas apenas tentativamente.

No sensoriamento remoto, um dos aspectos mais relevantes para estudos de geologia estrutural é a abordagem dentro do âmbito espacial e temporal. Enquanto o primeiro tor na possiveis as observações das principais estruturas através da análise dos padrões texturais e formas geomór ficas, o segundo permite analisar as variações de suas expressões pelo realçamento sazonal. O realce sazonal das feições é o principal motivo do por quê da análise de várias imagens Landsat de diferentes épocas fornecer mais informação do que aquela contida numa cena de uma única estação do ano. As variações na iluminação da ce na através de variações do azimute e ângulo de elevação solar em imagens de épocas diferentes podem acentuar a textura superficial e o padrão topográfico, devido ao realce por sombreamento, produzindo efeitos similares aos 
obtidos pelos sistemas de radar de visada lateral,e que são bastante vantajosos na interpretação de estruturas geológicas.

Contudo, estas variações do azimute e ângulo de eleva ção solar podem ocasionar tendenciosidades na amostragem das feiçoes estruturais extraídas das imagens Landsat, principalmente em relação aos lineamentos. As imagens de radar também ostentam efeitos similares conforme se ja a direção de iluminação (ou visada) do sistema. De $\underline{s}$ te modo, o uso conjunto de imagens Landsat(RBV e MSS) e de radar pode minimizar estas deficiências e aumentar a quantidade e confiabilidade das informaçóes estruturais adquiridas, através de um processo interativo de inter pretação. Isto se reverte numa importante questão, uma vez que os lineamentos são as principais feiçoes estru turais exibidas por essas imagens.

Devido à numerosa quantidade de lineamentos que frequen temente é extraída dessas imagens, a sua classificaçăo torna-se um procedimento preponderante para análise das informações estruturais que contêm. Disto advém a ne cessidade do desenvolvimento e aplicação de uma criterio sa metodologia de trabalho, motivação maior do presente estudo. $\mathrm{Na}$ pesquisa realizada sobre os lineamentos do Estado do Rio de Janeiro, esta metodologia resume-se ba sicamente numa seqüência ordenada de três etapas que en volvem: a) identificação, que é o reconhecimento das feições naturais lineares da superfície, tais como va les, cristas e escarpas retilíneas, segmentos retilíneos de drenagem, depressões ou lagos alongados, descontinui dades retilineas de terrenos texturalmente distintos, feições tonais lineares, etc.; b) extração, que consis te em cartografar a exata forma com que a imagem exibe - lineamento; c) análise, que envolve uma gama de obser vações acerca da direção, distribuição e padrão espa cial, densidade, comprimento relativo, curvilinearidade, grau de expressão no terreno, relações de intersecção e angularidade, continuidade ou descontinuidade da feição linear, etc.. Desta análise os lineamentos são classí ficados em sistemas e subsistemas, que devem mostrar coe rência para permitir uma interpretação estrutural ade quada.

Embora estejamos conscientes de que os lineamentos re presentam apenas uma parcela dos tipos de estruturas existentes na área e que na evolução estrutural não ne cessariamente são os mais importantes, na ausência de outros dados procurou-se investigar as possiveis rela ções existentes entre as principais estruturas de cará ter regional tais como o Lineamento de Além Paraíba, as faixas cataclásticas do nordeste do Estado, os plútons da Serra do Mar e os sistemas de fraturas, todos já cí tados na literatura geológica. O esboço da evolução es 
trutural e tectônica resultante desta análise é por tal fato meramente especulativo e sua pretensão, neste tra balho, é a de deixar documentada uma hipótese de inte $\underline{r}$ pretação que possa ser confrontada com dados estruturais mais detalhados no futuro.

Abstract: Gathering data on a scale in agreement with the type of geological features being analysed is the basic principle of remote sensing application to structural studies. The influence of many forms of structures on geomorphology is so conspicuous that structural studies on a regional scale utilize topographic analysis as the principal criterion for the interpretation of features with geological significance.

However, it is necessary to have the most appropriate means and methods so that such features can be analysed in the context of their regional dimensions. Orbital remote sensing provides the means, mainly through Landsat images, as one of the major alternatives for the study of important aspects of certain structural features. Obviously, the use of any single tool does not satisfy all the requirements in structural studies. The use of remote sensing data for the propositions of structural models or more extensive deductions, such as, for instance, of tectonic evolution, will be necessary in conjunction with other informations or other types of data. Without such integration of data or informations, the propositions or deductions based on the models found in the literature will be able to be formulated only tentatively.

Relevant aspects of Landsat imagery in the study of structural geology include spatial and temporal characteristics. The former makes it possible to view major structural features through the analysis of geomorphic forms, patterns and textures, while the latter provides seasonal enhancement fo the terrain features. Seasonal enhancement of geomorphic features is the main reason that multi-seasonal analysis of Landsat imagery provides more structural informations than what can be obtained from one scene only. Variations in the sun's elevation and azimuth can accentuate terrain texture and topographic pattern due to shadow effects very similar to those observed in side-looking radar where shadow enhancement is used advantageously in the interpretation of geologic structures.

Nevertheless, structural features extracted from Landsat imagery are biased by sun's azimuth and elevation, while in Slar imagery they are biased by the illumination direction of the radar system. In this way, the concomitant use of Landsat (MSS and RBV) and Slar may liminate these deficiencies and increase the amount and reliability of structural information extracted through an interactive 
process of image interpretation. This is an important point since lineaments are the main structural features observed in such images.

The classification of the numerous lineaments exhibited by these images is a weighty procedure in lineament analysis and reveals the necessity of development and application of a sound methodology, which is the main goal of this study. The methodology applied to extract lineaments in the State of Rio de Janeiro may be summarized into a sequential procedure consisting of three steps: a) identification of the natural terrain features, such as rectilinear valleys, ridges, scarps, segments of drainages, elongated depressions and lakes, rectilinear discontinuities of terrain textures, linear terrain features, etc.; b) extraction of the linear features in their exact form as observed in the images; c) analysis of the lineaments including their direction, spatial distribution pattern and density, relative length, degree of terrain expression, mutual relationship and intersecting angles, continuity and discontinuity of the linear features, etc. From this analysis,lineaments in the State of Rio de Janeiro are classified into systems and subsystems from which the structural significance of the lineaments may be tentatively inferred.

Even though lineaments may represent only a small part of the diverse types of structures found in the area and may not necessarily be the most important in structural evolution, the study sought to investigate a possible relationship among the main regional structures, in the obsence of other data. Examples of such structures are the "Além Paraíba" lineament, the cataclastic belts in the northeastern portion of the State, the plutons and the fracture system of "Serra do Mar", all of them discussed in the literature. The resulting attempt to have a sketch of the structural and tectonic evolution of the area, based on this analysis, is merely speculative and its objective is to document an interpretation hypothesis that will be used to confront with detailed structural data in the future.

COTTAS, Luiz Roberto

Estudos geológico-geotécnicos aplicados ao planejamento urbano de Rio Claro, SP. 30 de janeiro. $171 \mathrm{p}$.

Orientador: Vicente José Fúlfaro

Resumo: Este trabalho procura mostrar a grande diversidade dos problemas geológicos referentes ao desenvolvimento de centros urbanos brasileiros e sugere uma metodologia ade quada de abordagem destes condicionantes, com vistas à elaboração de planos diretores municipais.

o método compreende quatro categorias de estudos. A prí 
meira trata de aspectos básicos da área urbana, tais co mo topografia, relevo e constituição de rochas e mat $\underline{e}$ riais de cobertura. A segunda visa a estudar as proprie dades geotécnicas das rochas e solos e as cararterísti cas dos potenciais hídricos tanto das águas superficiais como subterrâneas. Na terceira categoria, são utiliza dos os resultados obtidos nas duas outras para se defi nirem as adequabilidades de áreas a utilizações, que dé pendem do quadro geológico-geotécnico da área. Estas compreendem fundações de prédios, sub-leitos de vias, instalações de obras subterrâneas, disposição de lixo e de material de esgoto e extração de recursos minerais. São ainda, demarcadas as áreas sujeitas a riscos geoló gicos, tais como erosão acelerada, instabilidade de en costas e enchentes. A última categoria de estudos con siste em se utilizarem todas as informações obtidas pá ra a organização de uma carta que orienta onde o meió físico é mais adequado à ocupação dos diferentes setó res urbanos (industrial, comercial, residencial e de cí culação), e qual deve ser a ordem de prioridade desta ocupação.

o método proposto foi aplicado na área de desenvolvimen to urbano da cidade paulista de Rio Claro, sendo confé cionadas quatorze cartas que mostram aspectos geológicogeotécnicos da área, entre elas a de indicações da Geo logia para a melhor ocupação urbana.

Abstract: The aim of the present work is to demonstrate the wide diversity of geological problems related to the development of Brazilian urban centers and to suggest adequate methods of approach to solve these problems and elaborate plans for land use in municipal areas.

The method adopted consists of four types of studies. The first deals with basic aspects of urban areas such as topography, relief, constitution of rocks and soil cover. Secondly, the method involves a study of the geotechnical properties of rocks and soils, and surface and groundwater potentials. In the third type of study, results obtained from the two previous studies are used to define the suitability of an area for utilization depending on geological-geotechnical character of the area. This encompasses foundation for buildings and roads, installation of underground structures, garbage and waste disposal and extraction of mineral resources. Also included in this are geological hazards such as rapid erosion, slope instability and floods. The final study sums up and uses all the information obtained in order to organize a map for the purpose of representing different urban sectors that are most suitable for occupation, whether industrial, commercial, residential or circulation, and to establish their order of priority. 
.54 .

The method proposed was applied to an area under urban development in Rio Claro city, São Paulo State, and fourteen maps were prepared to show the geologicalgeotechnical aspects of the area including one with geological indication for a better occupation of urban land areas.

MACHADO, Rômulo

Evolução geológica, análise estrutural e metamórfica da região de Vassouras e Paracambi, porção ocidental do Estado do Rio de Ja neiro. 12 de dezembro. 196p.

Orientador: Marcos Aurélio Farias de Oliveira

Resumo: Esta tese discute a evolução geológica-metamórfica e es trutural - e a correlação lito-estrutural de um setor da Faixa Paraíba do Sul, porção ocidental do Estado do Rio de Janeiro, nas regióes de Vassouras e Paracambi, basean do-se em dados petrográficos e estruturais e um mapa geológico na escala de 1:100.000.

São reconhecidas seis seqüências lito-estruturais, a sa ber: 1) Seqüência de Valença - rochas granulíticas e charnoquíticas; 2) Seqüência do Quirino - biotita (hornblenda) plagioclásio-gnaisse migmatizado com migma titos bandados e anfibolitos associados; 3 ) Seqüência de Barão de Vassouras - biotita gnaisse migmatizado com gnaisses granitóides, rochas graniticas e cataclásticas, com níveis de calcossilicáticas e mármores associados; 4) Seqüência de Vassouras - rochas granitóides, migma titicas e cataclásticas associadas; 5) Seqüência de Paracambi - gnaisse granitóide porfiroblástico migmati zado com niveis de gnaisse kinzigitico, anfibolitos e calcossilicáticas; 6) Seqüência de Japeri - migmati tos homogêneos e heterogêneos com gnaisses, granitóides e granitos associados. Estas seqüências lito-estruturais são relacionadas às Séries (Grupos) Juiz de Fora e Paraí ba de Ebert (1956) e à Série (Grupo) da Serra dos Ór gãos de Rosier (1965). As análises petrográficas reve laram composição tonalítica e quartzo diorítica para a primeira seqüência; granítica a tonalítica e monzodio ritica a quartzo dioritica para a segunda; granítica $\bar{e}$ granodiorítica para as terceira, quarta e quinta seqüên cias; e granitica a tonalítica e quartzo dioritica pá ra a sexta seqüência.

As relações texturais destas rochas (seqüências)indicam a atuação conjunta de processos de deformação e recrís talização em pelo menos duas fases, cujos registros são observados nos porfiroclastos e nos cristais da matriz. o metamorfismo atingiu os fácies granulito e anfibolito alto, ambos de pressão média.

São caracterizadas quatro fases de dobramentos superpos tos. A primeira e a segunda, identificadas respectiva 
mente por $D n$ e $D n+1$, apresentam dobras cerradas e isocli nais que afetam o mobilizado $M n$; as demais, $D n+2$ e $D n+3$, são fechadas a suaves e afetam o mobilizado $M n+1$. As três primeiras fases mostram orientações axiais aproxí madamente NE-SW, e a quarta, NW-SE.

O magmatismo é expresso por cinco grupo de rochas ígneas: ortoanfibolitos de composição básica e ultramáfica, gra nitóides sintectônicos com migmatitos associados, gran $\underline{i}$ tos tardi e pós-tectônicos, rochas básicas e rochas al calinas.

Abstract: This thesis discusses the geologic (metamorphic and structural) evolution and lithostructural correlation in a section of the Paraiba do Sul zone in the Vassouras and Paracambi regions, western part of the State of Rio de Janeiro, based on petrographic and structural studies and geologic mapping a scale of $1: 100.000$.

Six informal lithostructural sequences are distinguished: 1) The Valença Sequence - granulitic and charnockitic rocks; 2) The Quirino Sequence - migmatized biotite (hornblende) plagioclase gneisses with associated banded migmatites and amphibolites; 3) The Barão de Vassouras Sequence - migmatized biotite gneiss with associated marble; 4) The Vassouras Sequence - granitoids, migmatites and associated cataclastic rocks; 5) The Paracambi Sequence - migmatized porphyroblastic granitoid gneiss with kinzigitic gneiss and calc-silicate intercalations; and 6) The Japeri Sequence - homogeneous to heterogeneous migmatites with associated gneiss, granitoid and granitic rocks. These sequences may be correlated with the Juiz de Fora and Paraíba "Series" (Groups) of Ebert (19.56) and the Serra dos Órgãos "Series" (Group) of Rosier (1965). Petrographic analysis revealed tonalitic and quartz-dioritic compositions for the second sequence; granitic and granodioritic compositions for the third, fourth and fifth sequences; granitic to tonalitic and quartz-dioritic compositions for the sixth sequence.

The textural relations of these rocks indicate the interaction of the deformation and recrystallization processes, for at least two different phases, as recorded in the porphyroclasts and matrix.

Metamorphism took place under conditions of medium pressure and reached the granulite and high amphibolite facies. Four folding phases are recognized: the first and second phases, Dn and $D n+1$, exibit tight to isoclinal folds that affected the first phase of migmatization ( $M n$ ), whereas the others, $D n+2$ and $D n+3$, exibit closed to gentle folds and affected $M n+1$. The first three phases of folding show axial trends approximately NE-SW, and the fourth, NW-SE.

Five groups of igneous rocks are distinguished: basic 
and ultramafic ortoamphibolites; syntectonic granitoids with associated migmatites; late and post-tectonic granites; basic dikes and sills; and intrusive alkaline rocks.

\section{PACHECO, Alberto}

Análise das características técnicas e da legislação para uso e proteção das águas subterrâneas em meio urbano (Município de São Paulo). 18 de maio. $174 p$.

Orientador: Aldo da Cunha Rebouças

Resumo: As águas subterrâneas da Região Metropolitana da Grande São Paulo desempenham um papel extremamente importante como recurso complementar, destacando-se o seu valor só cio-econômico e estratégico.

$\mathrm{Na}$ parte central do Município de São Paulo inventariamos 475 poços tubulares distribuídos em três zonas, uma de ocupação predominantemente residencial e comercial, ou tra de ocupação predominantemente industrial e outra mis ta.

A qualidade técnica construtiva de $55 \%$ dos poços é boa, enquanto $45 \%$ apresentam deficiências técnicas que são ex tremamente graves, mormente quando o maior volume dé água extraída se destina ao consumo humano, hospitalar, hoteleiro e indústrias alimentícias.

Dentre as deficiências destacam-se: falta de cimenta ção; de laje de proteção; de tampa; locação junto a depósitos de sucatas e produtos químicos, cemitérios e postos de serviços, negliglência ou ignorância dos ris cos de contaminação decorrentes.

É de vital importância que medidas de ordem institucio nal e técnica sejam urgentemente tomadas, com vista ao uso e preservação da qualidade das águas subterrâneas. Conseqüentemente, são descritas e analisadas as legisla ções de alguns países e do Brasil e apresentadas suges tões para uma efetiva proteção das águas subterrâneas no meio urbano.

Abstract: Ground water of the Metropolitan Grande São Paulo Region have an extremely important role as a complementary resource, emphasizing its strategic and economical-social value.

At São Paulo Município central part we have drawn up an inventory of 475 wells, situated in three sectors, one residential and commercial, other industrial and the other mixed.

The constructive technical quality of $55 \%$ from wells is good, while $45 \%$ present technical faults which are extremely serious, mainly when the greatest volume of exploited water goes itself to the human consumption, hospital, hotel and nutritive industries. 
Among the deficiencies we can detach: lack of cimentation; plate of cimentation; lack of cap; area near the junk yard and chemical products, cemeteries and service station, negligence or ignorance concerning the contamination dangers.

It is essential that technical and institucional rules are urgenty taken in order to preserve the ground water quality. Therefore some countrie's legislations and also Brasil's have been described and analised and suggestions have been presented in order to protect the ground water in the urban way.

PANIAGUA, Remy David Antezana

Dispersão de ondas superficiais na Plataforma Sul-Americana.

20 de novembro. 71p. 39 apêndices.

Orientador: Georg Robert Sadowski

Resumo: Com o propósito de determinar a estrutura e caracterís ticas da crosta e manto superior na Plataforma Sul-Amé ricana foi estudada a dispersão das ondas superficiais com períodos entre 10 e 50 s.

Selecionaram-se 13 sismos, com epicentros distribuídos no continente de tal forma que permita uma boa cobertú ra da Plataforma Sul-Americana. Os sismogramas de perío do longo utilizados são das estações sismográficas de Brasilia, Rio de Janeiro, Natal e La Paz (Bolívia).

As ondas superficiais dos sismos selecionados foram ana lisados mediante a técnica de Filtragem Múltipla; o re sultado é uma matriz de amplitudes em função da velocí dade de grupo e do período. As curvas de dispersão teó ricas foram determinadas usando-se o método matricial de Thomson-Haskell.

A comparação entre os valores de dispersão teóricas e observados permitiu obter um modelo crustal representa tivo da região dos escudos do Brasil Central e Atlânt co. A espessura da crosta, segundo esse modelo, é dé $40 \mathrm{~km}$.

As variações das velocidades de grupo das ondas Rayleigh para períodos inferiores a $20 \mathrm{~s}$, observadas na maioria dos sismos estudados, parecem estar associadas à presen ça da cadeia andina ou de bacias sedimentares, na trajē tória das ondas superficiais.

Comparando-se a curva média de dispersão das ondas Rayleigh representativa da região dos escudos do Brasil Central e Atlântico, com suas similares de outras regizes de escudo, encontrou-se uma boa semelhança com a estru tura crustal da região afroasiática.

Abstract: Surface wave dispersion analysis for periods between 10 and $50 \mathrm{sec}$ have been accomplished to study the crust and 
upper mantle structure.

Thirteen South-American events with paths crossing the South American platform were selected. Long period seismograms from Brasilia, Rio de Janeiro, Natal and La Paz (Bolivia) seismographic stations have been used.

Multiple Filter Techniques were used to analyze surface wave dispersion; this method gives amplitudes as a function of group velocity and period. Theoretical dispersion curves were obtained by using the ThomsonHaskell Matrix Method.

A crustal model for the Central Brazil and Atlantic shields were obtained by comparing theoretical and observational dispersion curves. This model indicates a crust thickness of $40 \mathrm{~km}$.

Group velocity variations of Rayleigh waves, for periods under 20sec., were observed in almost all cases; these variations seem to be associated to the presence of Andean Chain or sedimentary basin, along the path of surface waves.

The comparison of the mean dispersion curve for Central Brazil and Atlantic shields with dispersion curves for other cratonic regions, showed a similarity with AfroAsiatic crustal structure.

RAGONHA, Evaldo Wehmuth

Taxionomia de dentes e espinhos isolados de Xenacanthodii (Chon drichthyes, elasmobranchii) da Formação Corumbataí. Considera ções cronológicas e paleoambientais. 12 de novembro. 166p.

Orientador: Rubens da Silva Santos

Resumo: A Formação Corumbataí da Bacia do Paraná abriga uma r $\underline{i}$ ca e diversificada paleoictiofauna até então muito pou co conhecida. Vários representantes das Classes Osteich thyes e Chondrichthyes acham-se dispersos nos seus sedí mentos. No que concerne aos condrictes, a ordem Xena canthodii - tida como um primitivo ramo lateral da li nha principal de evolução dos elasmobrânquios, cujos representantes foram dulciaquícolas - tão bem conhecida no Hemisfério Norte, também aqui se faz presente por meio de diferentes formas de dentes e espinhos cefáli cos.

Levando-se em conta o caráter cartilaginoso do esquele to, raríssimas são as formas conhecidas no mundo cuja descrição tenha se baseado neste particular. Assim, é que a maior parte das espécies que integram essa ordem são conhecidas com base na morfologia de dentes e/ou es pinhos cefálicos.

Quatro espécies são aqui descritas levando-se em conta dentes isolados. Destas, três são espécies novas: Xena $\underline{\text { canthus angatubensis; }} \underline{x}$. camaquensis e $\underline{x}$. ferrazensis e a quarta, Xenacanthus moorei (K'oodward, 1889), ante 
riormente só conhecida no Hemisfério Norte, é agora, pe la primeira vez, registrada no Hemisfério Sul, demons trando, com efeito, que nem toda a fauna da Formação co rumbatai fora endêmica.

No que concerne a espinhos cefálicos isolados, pela prí meira vez, espécies do gênero Xenacanthus tornam-se có nhecidas na bacia sedimentar do Paraná. Três exemplā res foram diagnosticados, sendo dois tratados como espé cies novas: $\underline{x}$. santaritensis e $\underline{x}$. taquaritubensis; $\underline{0}$ terceiro - cuja porção proximal mostra-se dilatada, com aparência de bulbo - se converte na segunda ocorrência mundial relatada com base nesse conspícuo carácter.

Consideraçóes a respeito do habitat, hábito, morfologia funcional e distribuição geológica dos elementos que com prem esse grupo de tubarôs, em adição a outros grupośs fósseis de animais e vegetais também presentes na forma ção, aliados aos aspectos físicos das rochas, forneceram elementos capazes a um nova conceituação quanto ao paleo ambiente que teria predominado nos tempos de deposição dos sedimentos que caracterizam a Formação Corumbataí: - domínio de um sistema lacustre em planície de inunda ção sobre outros sistemas deposicionais eventualmente atuantes.

A presença de Xenacanthus moorei, e outros elementos da paleoictiofauna que se lha associam, propendem à aceita ção de uma idade triássica (possivelmente Carniano) aos termos que se julga finais desta tão conhecida formação geológica.

Abstract: The Corumbataí Formation of the Paraná Basin contains a rich and diversified paleoichthyofauna little known up to now. Various representatives of the Osteichthyes and Chondrichthyes are found dispersed in the sediments. As regards the Chondrichthyes, the order Xenacanthodii considered as a primitive branch of the main evolutionary line of the elasmobranchs, whose members were freshwater forms - so well known in the northern hemisphere - are also represented here by different forms of teeth and cephalic spines. If we take into account that most of them had cartilaginous skeletons, it is not surprising that the number of forms described on this basis are so exceedingly rare. Most of the species in this order are therefore recognized by the morphology of their teeth and cephalic spines.

Four species are described here on the basis of isolated teeth: three of these are new species, xenacanthus an fatubensis, $\underline{x}$. camaquensis and $x$. ferrazensis, plus a fouth Xenacanthus moorei (Woodward, 1889), previously known only in the northern hemisphere, and now recorded for the first time from the southern hemisphere - a compelling evidence that not all the fauna of Corumbatai 
.60 .

Formation was endemic.

As far as the isolated cephalic spines are concerned, species of the genus Xenacanthus are recognised for the first time in the sedimentary Paraná basin. Of these, three are diagnostic, two of which are new species: $\underline{x}$. santaritensis and $\underline{x}$. taqueritubensis; the third whose proximal part is dilated in the form of a bulb, is the second occurrence in the world with this conspicuous character.

Considerations regarding the habitat, habits, functional morphology and geological distribution of this group of shark like fishes, in addition to other animal and plant fossils also belonging to the formation, together with the physical aspect of the rocks, offer elements which enable us to establish new concepts as to the prevailing paleoenvironment at the time of deposition of the sediments that characterize the Corumbatai formation: a predominance of lacustrine system within flood plains compared to other possible depositional systems of this period.

The presence of Xenacanthus moorei and other elements of paleoichthyofauna associated with them favour a Triassic age (possibly Carnian) for the deposits considered to be the upper part of the sedimentary sequence of this well known geological formation.

RUBERTI, Excelso

Petrologia do maciço alcalino do Banhadão, PR. 25 de junho. 248p. Orientador: Celso de Barros Gomes

Resumo: 0 maciço do Banhadăo representa um dos muitos centros magmáticos de caráter alcalino, ocorridos entre o final do jurássico e cretáceo inferior, intrusivos nos flancos do grande arqueamento de Ponta Grossa. Acha-se situado a noroeste da localidade de Cerro Azul, Estado do Para ná, e tem como coordenadas geográficas aproximadas $24^{\circ} 39^{\prime}$ 's e $49^{\circ} 23^{\prime}$ 'W.G.

- complexo constitui uma massa heterogênea de litologias exclusivamente insaturadas encaixadas em rochas graniti cas do Complexo Três Córregos. As variações mineralógi cas e texturais presentes permitem individualizar três associações magmáticas de caráter definido, consolidadas em condições geológicas distintas. A primeira perten cem diversas variedades de nefelina sienitos de granula ção grossa que evoluem, gradativa e quimicamente, de ul trabásica até intermediária, na seguinte seqüência: me lanita-nefelina sienitos $\rightarrow$ nefelina sienitos $I \rightarrow$ nefeli na sienitos II-róseos $\rightarrow$ nefelina sienitos II-cinzas. A segunda inclui rochas de natureza ultrabásica a básica, de granulação fina a média, representadas quase que un $\underline{i}$ camente por flogopita melteigitos; nela também se enqua dram os malignitos e os feldspatos-melanita ijolitos or $\underline{i}$ 
ginados em conseqüência da ação intrusiva daquelas ro chas sobre as encaixantes (nefelina sienitos II-róseos e cinzas). Finalmente, a terceira engloba todas as rochas de granulação fina até afanítica ocorrendo na forma de diques, que retalham as diversas variedades de nefelina sienitos, e denominadas genericamente de fonolitos.

Quanto ao quimismo, as rochas do complexo são fortemen te alcalinas e se enquadram na série alcalina de Peacock (1931) e classe hiperalcalina de Almeida (1961). As pe quenas concentraçóes de $U$, Th e sobretudo terras raras, a ausência de minerais tidos como raros e a presença constante de apatita e titanita nas diversas litologias confirmam o caráter tipicamente "miasquítico" do comple xo. As diversas variedades de nefelina sienitos exibem evidências de terem sido submetidas à diferenciação, co mo indicado pelo enriquecimento em $\mathrm{Al}_{2} \mathrm{O}_{3}, \mathrm{~K}_{2} \mathrm{O}$ e $\mathrm{Na}_{2} \mathrm{O}$ e empobrecimento em $\mathrm{TiO}_{2}$, $\mathrm{Fe}$ (total) e $\mathrm{CaO}^{3}$. Os elementos traços $\mathrm{Zr}$, Nb, Y e $V$ acham-se concentrados nas rochas portadoras de melanita. Os flogopita melteigitos e ro chas associadas possuem as maiores concentraç⿸丆es de $\mathrm{TiO}_{2}$, $\mathrm{Fe}$ (total), MgO e $\mathrm{CaO}$ e as mais baixas de $\mathrm{Al}_{2} \mathrm{O}_{3}, \mathrm{~K}_{2} \mathrm{O}^{2}$ ' $\mathrm{Na}_{2} \mathrm{O}$ relativamente às demais do maciço; quanto aos tra ços, são praticamente as únicas a conterem $\mathrm{Ni}, \mathrm{Cu}$ e $\mathrm{Cr}$, além de teores anômalos de Ba. Os fonolitos são quimi camente semelhantes às variedades de nefelina sienitos. As determinações radiométricas pelo método $\mathrm{K}-\mathrm{Ar}$ fornece ram idade de $127 \mathrm{~m}$.a. para um micro melanita - nefelina sienito (do conduto secundário do maciço), correlaciona do à primeira manifestação magmática. Os flogopita me 1 teigitos intrusivos em nefelina sienitos II - róseos e cinzas acusaram idade ao redor de $108 \mathrm{~m} . a$. , enquanto que os fonolitos no intervalo 95 e $102 \mathrm{~m} . \mathrm{a}$..

o estudo químico detalhado dos minerais mais abundantes do complexo mostra algumas características distintivas. A nefelina acha-se representada quase que unicamente pe la variedade "médio-potássica". No entanto, o seu teor de "sílica em excesso" depende da rocha em que se encon tra; é variável nos nefelina sienitos II-róseos e cin zas, situando-se ora no campo de convergência "MorozewiczBuerger", com temperaturas entre 500 e $600^{\circ} \mathrm{C}$, ora fora dele, com temperaturas da ordem de $750^{\circ} \mathrm{C}$. Esse teor é mais alto nos fonolitos, revelando cristalização ao re dor de $775^{\circ} \mathrm{C}$, e mais baixo nas demais rochas, com a com posição se aproximando da de Buerger e correspondendo aó equilíbrio químico de temperaturas submagmáticas, infe riores a $500^{\circ} \mathrm{C}$. Os feldspatos alcalinos consistem de ortoclásio pertítico na maioria das rochas, à exceção dos malignitos, feldspato-melanita ijolitos e alguns me lanita-nefelina sienitos, onde são provavelmente micró clínio, e dos fonolitos, onde constituem com certeza sa nidina. A composição é essencialmente potássica, com 
Or > 89\%; contudo, nos nefelina sienitos II-róseos e cinzas, o mineral exibe ampla variação com valores com preendidos entre $\mathrm{Or}_{94,4}$ e $\mathrm{Or}_{58} 6^{\circ}$ Os piroxênios têm com posição variável confórme a nătưreza química da rocha $\bar{e}$ as condições de cristalização; essa composição abrange todos os termos da série: soda-augita, egirina-augita e egirina.

Dos minerais de cristalização tardia, destacam-se as mi cas, apresentando amplas variações na relação $\mathrm{Mg}: \mathrm{Fe}$; em geral correspondem à biotita, sendo flogopita uma varie dade mais rara. A melanita é um mineral primário (mi crofenocristal e constituinte da matriz), um produto da transformação de piroxênios, ou então, resulta da crís talização de soluções residuais do magma; todavia, em todos os casos ela tem natureza essencialmente cálcicaférrica, aparecendo andradita como um componente básico molecular. Intercrescimento feldspato potássico com ne felina é peculiar dos nefelina sienitos $I$, tendo se for mado a partir da cristalização de resíduo magmático en riquecido de $\mathrm{Na}$ e K; sua composição é similar em tudo à dos feldspatos alcalinos e da nefelina de cristais iso lados formados previamente.

Os resultados coligidos neste estudo sugerem que as ro chas do complexo alcalino do Banhadão derivaram de su cessivas intrusões de caráter petrológico definido, a partir de magmas bem distintos; um magma de composição nefelinitica teria se diferenciado gerando as diversas variedades de nefelina sienitos e fonolitos; um outro, de composição ferromagnesiana enriquecida em álcalis te ria dado origem aos flogopita melteigitos e rochas assó ciadas. Aparentemente, são magmas alcalinos de carátēr primário, originados pela fusão direta de rochas da re gião basal da crosta ou do manto superior.

Abstract: The alkaline massif of Banhadão, located near Cerro Azul, State of Paraná ( $24^{\circ} 39^{\prime} \mathrm{S}$ and $49^{\circ} 23^{\prime} \mathrm{W}$ ), is one of a series of alkaline igneous intrusions emplaced during the Late Jurassic and Early Cretaceous along the flanks of the Ponta Grossa Arch.

The Banhadão complex intrudes the Três Córregos granite batholith; it is a composite body consisting solely of undersaturated rocks. The following magmatic associations can be distinguished on the basis of mineralogic and textural variations, each association representing different geological conditions of formations: 1) a suite of very coarse nepheline syenites that gradually pass from ultrabasic to intermediate composition (melanite-nepheline syenites $\rightarrow$ nepheline syenites $I \rightarrow$ light reddish nepheline syenites II $\rightarrow$ gray syenites II); 2) medium to fine grained ultrabasic to basic rocks represented almost exclusively by phlogopite 
melteigites, with minor amounts of malignites and feldspar-melanite ijolites, thought to have formed through reactions between the melteigites and light reddish and gray nepheline syenite II country rocks; 3) fine-grained to aphanitic phonolitic dikes that cut the various nepheline syenites.

The rocks of the complex are strongly alkaline, falling within the alkaline series of Peacock (1931) and the hyper-alkaline class of Almeida (1961). Rocks of the complex are mainly miaskitic, as attested by,among other characteristics, the low concentration in trace elements ( $V$, Th and mainly REE), lack of rare-metal silicates, and relative abundance of apatite and titanite in all lithologies. Nevertheless, many nepheline syenites are distinguished by a differentiation trend in which highly differentiated end members are enriched in alcalis and $\mathrm{Al}_{2} \mathrm{O}_{3}$, and at the same time show decrease in $\mathrm{MgO}$, $\mathrm{FeO}$ (total), $\mathrm{CaO}$ and $\mathrm{TiO}_{2}$. The less differentiated melaniterich rocks, on the other hand, show higher concentrations in $\mathrm{Zr}, \mathrm{Nb}, \mathrm{Y}$ and $\mathrm{V}$. Phlogopite melteigites and associated rocks show the highest contents of $\mathrm{MgO}, \mathrm{FeO}$ (total), $\mathrm{CaO}$ and $\mathrm{TiO}_{2}$, and the lowest concentration of alcalis and $\mathrm{Al}_{2} \mathrm{O}_{3}$; they are significantly enriched in $\mathrm{Ba}$ and are the only rocks with detectable amounts of $\mathrm{Ni}, \mathrm{Cu}$ and $\mathrm{Cr}$. The phonolites are chemically similar to the varieties of nepheline syenites.

Radiometric age-dating using the $K-A r$ method furnished the following results: an age of $127 \pm 3 \mathrm{~m} . \mathrm{y}$. for a micromelanite-nepheline syenite from a small pipe, which is interpreted as dating the initial magmatic events; an age of $108 \pm 6 \mathrm{~m} . \mathrm{y}$. for a phlogopite melteigite, intrusive into light reddish and gray nepheline syenites II; and ages between $95 \pm 3 \mathrm{~m} . \mathrm{y}$. and $102 \pm 3 \mathrm{~m} . \mathrm{y}$. for the phonolites. Detailed chemical studies of main rock-forming minerals reveal several distinctive characteristics. The nephelines are almost entirely of the meso-potassic variety. In the nepheline syenites II, the nephelines show a composition which falls within the Morozewicz-Buerger convergence field, indicative of temperatures of formation between $500-600^{\circ} \mathrm{C}$; some nephelines exhibit compositions which are compatible with formation temperatures around $750^{\circ} \mathrm{C}$. Excess silica in nephelines is in general higher in phonolites, suggesting crystalization around $775^{\circ} \mathrm{C}$. In other rocks (melanite-nepheline syenites, nepheline syenites I, malignites and feldspar-melanite ijolites) nephelines cluster around the Buerger composition, corresponding thus to a possible submagmatic recrystallization at $500^{\circ} \mathrm{C}$, or lower.

The K-feldspars are perthitic ortoclases in the majority of rocks of the complex with the exception of malignites, feldspar-melanite ijolites and melanite-nepheline syenites, 
.64 .

where they are probably microcline, and of phonolites, where they are sanidine. The $K$-feldspars usually have a strongly potassic composition ( $\mathrm{Or}>85 \%$ ), but in the nepheline syenites II, they show a large variation in the $A b$ content, with values of $0 \mathrm{r}$ between 94,4 and $58,6 \%$. Intergrowths between $\mathrm{K}$-feldspar and nepheline are peculiar to the nepheline syenites $I$ and have crystallized from a magmatic residue enriched in $\mathrm{Na}$ and $\mathrm{K}$. Their compositions are similar to those of earlier formed individual K-feldspar and nepheline crystals.

Pyroxene composition changes according to rock types; soda-augites are dominant in phlogopite melteigites, melanite-nepheline syenites and feldspar-melanite ijolites. Aegirine-augites prevail in nepheline syenites I, nepheline syenites II, phonolites and some malignites; and aegirine-augites, together with aegirines, are found in some nepheline syenites II.

Micas crystallized late and show large variations in their Mg/Fe ratios. Biotite is more common than phlogopite.

Melanites formed principally by reaction between pyroxenes and titanite; to a lesser extent, they were derived from residual solutions or are primary. Independent of their origin, they are essentially calcic-ferric varieties with andradite as a basic molecular component.

This study suggests that the rocks of the alkaline complex of Banhadão were formed during sucessive intrusions of two different magmas types. A nephelinitic magma may have differentiated to form

and phonolites. A ferro-magnesian magma enriched in alkali may have been responsible for the formation of phlogite melteigites and related rocks. Both magmas were probably primary alkaline magmas directly derived by melting of rocks of the lower crust or the upper mantle.

SANTIAgo, Maria Marlúcia Freitas

Mecanismos de salinização em regiões semi-áridas. Estudo dos açu des Pereira de Miranda e Caxitoré no Ceará. 19 de dezembro. $176 \mathrm{p}$.

Orientadox: Aldo da Cunha Rebouças

Resumo: Estudou-se durante três anos, as bacias contribuintes dos açudes Pereira de Miranda e Caxitoré, em área de ro chas cristalinas no Ceará, para determinar os mecanis mos de salinizaçăo de suas águas, através de medidas iso tópicas (razão ${ }^{0} /{ }^{0}$ ) e hidroquímicas (determinações dos íons maiores) em águas superficiais, subterrâneas e de chuvas.

Desenvolveu-se um modelo isotópico para, durante os pe ríodos de estiagens, determinar as taxas de evaporação 
e percolação em açudes e comparou-se os resultados com os obtidos com o modelo químico convencional.

Como mecanismo de salinização dos açudes, foram quantí ficadas as contribuições das chuvas e da lixiviação do solo. Não foi notada uma interação açude-água subterrâa nea.

A salinização das águas subterrâneas é atribuída a recar gas com águas pluviais, durante o escoamento superfi cial, seguida por evaporação superficial da água na zó na capilar.

Abstract: During a period of three years the basins of the dams Pareira de Miranda and Caxiporá, located in the crystalline rock area of Ceará/Brazil, were studied in order to determine the mechapisms ${ }_{6}$ of salinization of their waters. Isotope methods $\left({ }^{0} /{ }_{0}\right)$ and hidrochemistry (determinations of the major ions) were applied to surface, underground and rain water in this study.

An isotope model was designed and applied to the determination of evaporation and percolation of dams in semi-arid zones during the dry season. The results are compared to those from a conventional chemical model.

As causes of salinization of the water in the dams the contributions of the rain itsef and the lixiviation of the soil are quantified. An interaction between the dams and the underground water is imperceptible.

The salinization of the underground water is attributed to recharge of the aquifer with rain water from the surface runoff followed by evaporation of the water rising, due to capilarity, in a one-directional flow to the surface.

SILVA, Adelbani Braz da

Análise morfoestrutural, hidrogeológica e hidroquímica no estudo do aqüífero cárstico do Jaíba, norte de Minas Geais. 15 de agos to. $190 p$.

Orientador: Sérgio Estanislau do Amaral

Resumo: Neste trabalho foram aplicadas técnicas de análise mor foestrutural, hidrogeológica e hidroquímica com objet $\bar{i}$ vo de definir as características e as potencialidades de um aqüífero cárstico localizado na região norte do Esta do de Minas Gerais. Essas técnicas permitiram o estudo da distribuição espacial e da freqüência das feições mor foestruturais (fraturas e dolinas), a orientação das frá turas e o comportamento regional dos parâmetros dimen sionais, hidrodinâmicos e hidroquímicos do aqüífero. $\bar{A}$ distribuição espacial das feições morfoestruturais evi denciou zonas com diferentes características do ponto de vista tectônico e de carstificação. Além disso, há evi dências de que as principais drenagens da área são conn 
.66 .

troladas por fraturamentos. Estatisticamente as fratu ras que mais ocorrem na área são as longitudinais com azimutes de 30 a 40 graus e as angulares com azimutes de 110 a 120 graus. As fraturas associadas às dolinas mais freqüentes sao as angulares orientadas entre 10 e 20 ou 110 e 120 graus e as transversais com azimutes entre 140 e 150 graus.

As fraturas longitudinais propiciaram a instalação de um carste mais raso enquanto que a carstificação ao longo das fraturas angulares e transversais atingiu maiores profundidades. Verificou-se também, que os niveis de carstificação não estão relacionados, de uma maneira ge ral, com o comprimento das fraturas ou ao tamanho das dolinas. A espessura saturada média é de $55 \mathrm{~m}$, a máxima superior a $100 \mathrm{~m}$ e a minima de $30 \mathrm{~m}$. Os recursos explo ráveis estimados são de $32.10^{6} \mathrm{~m}$ /ano. Estes recursos são acessiveis em vista da pouca profundidade do aqüífe ro e são favoráveis à exploração através de poços. As águas subterrâneas da área, de modo geral, não apresen tam restriçoes ao uso agrícola, humano e a alguhs tipos de indústrias. As principais restrições ao uso são re lativos à dureza e alcalinidade. Foram verificados tam bém, alguns focos de poluição na área em questão refle tindo a grande vulnerabilidade do aqüifero. Este fato sugere que é importante que sejam observados, na regiåo, os aspectos relacionados à conservação e preservaçăo dos recursos hídricos subterrâneos.

Abstract: Morphostructural, hydrogeological and hydrochemical techniques were applied in this study to characterize the groundwater system of the Jaiba Karst aquifer and its potencial for explotation and utilization as water supply to northern part of the state of Minas Gerais. The techniques allowed as the study of the spacial distribution and frequency of some morphological features, such as fracture and sinkholes as well as the regional behavior of dimensional and hydrodynamic parameters of the aquifer. From the point of view of tectonics and karstification, the spacial distribution of the morphological features exhibit zones with different characteristics. It was also seen that the level of karstification is generally independent of the length of the fractures and of the size of the sinkholes. In addition, there is evidence that the drainage of the principal streams is controlled by geological fracturing.

Statistically, the most frequently occuring fractures are longitudinal with azimuths from 30 up to 40 dregrees and angular fractures with azimuths from 100 up to 120 degrees. The fractures frequently associated with sinkholes are angular ( 10 up to 20 and 110 up to 120 degrees) and transversal, with azimuths between 140 and 150 degrees. 
The longitudinal fractures allowed a more shallow karst development while the karstification along the angular and transversal fractures was deeper. The average saturated thickness is $55 \mathrm{~m}$ with a maximum around $100 \mathrm{~m}$ and-a minimum of $30 \mathrm{~m}$. The $\sigma^{\text {estrimated sustainable }}$ groundwater yeld is about $32.10^{6} \mathrm{~m} /$ year. These groundwater resources are highly accessible by wells because of the snallow depth of the water table. The good groundwater quality in this region, in general, allows it be indicated for many types of agricultural, industrial and potables usages. The principal restriction on its usages is related to its hardness and alkalinity. In some parts of the aquifer were also found vestiges of pollution, so indicating its vulnerability to groundwater contamination. This fact suggests the importance of the statement of a groundwater protection program to insure the quality of this valuable resource.

SOARES, Rosa Maria Cotrim

Tratamento de dados químicos e petrográficos de rochas alcalinas do Brasil Meridional. 14 de novembro. $316 p$.

Orientador: Franco Levi

Resumo: Análises químicas e modais de rochas alcalinas compila das da literatura foram utilizadas para uma reavaliação de dados amostrais referentes às Províncias Petrográfi cas do Brasil Meridional. Foram determinados os parâme tros e indices da petrologia e traçados Diagramas de Vá riação, selecionados em função da literatura geológica com prioridade para aqueles escolhidos para representar províncias mundiais.

Técnicas estatisticas multivariantes, tais como,Análise de Agrupamento, Análise Discriminante e Análise Fato rial foram utilizadas com o objetivo de descrever e classificar os vários tipos petrográficos das províncias. Foram computadas também estatísticas amostrais e descri tivas dos elementos maiores em forma de óxidos e even tualmente dos elementos traços (em ppm), tanto para as unidades petrográficas, como maciços e para as rochas das províncias e, traçados histogramas e curvas de di tribuição de freqüência cumulativa.

Com base nos resultados obtidos pela combinação dos vá rios critérios foram delimitados vários campos composi cionais e comparados dados modais e mineralógicos norma tivos, além de dados sobre proporções em óxidos e catiô nicas. Os gráficos resultantes do tratamento dos dados químicos e petrográficos foram então integrados nos vários esquemas geotectônicos e petrológicos descritos na lite ratura.

Foi demonstrado que existe uma interrelação entre os grá ficos petrológicos clássicos e aqueles deduzidos da Aná 
.68 .

lise Estatistica Multivariante, principalmente a Análise Fatorial. As outras técnicas multivariantes tiveram ape nas efeito descritivo. Quanto aos histogramas, foram utilizados com bons resultados, principalmente na deli mitação de populações em função dos índices petrológicos ID e qz.

Com relação aos Diagramas de Variação verificou-se que os mais adequados na representação de associações petro gráficas e/ou províncias são aqueles que relacionam as composições modais e normativas (QLM e QAPF) porque além de definirem claramente os campos composisionais, permi tem avaliar os prováveis erros analíticos pelo confron to dos dados.

Abstract: Data from samples of alkaline rocks of $S$ and SE Brazil were re-evaluated in terms of chemical and modal analysis. By means of variation diagrams, petrological indexes and parameters were determinated and plotted,selecting the types that are most adequated to represent world provinces. In order to classify and describe compositional types and their fields, several multivariate statistical procedures were used: cluster, discriminant and factor analysis. Univariate statistics analysis of chemical elements in the form of oxides and occasionally trace elements data were also computed. Histograms and cumulative frequency curves were drawn for each massif and petrographic units belonging to the $S$ and SE Brazil "Province".

An integrative approach combines the chemical and petrological data into diagrams, in accordance with current geotectonic and petrological models. The results indicate limits of compositional fields by comparing norms, modes and data on oxide and cations proportions. Chemical graphs from petrology are clearly related to those of statistical methods, mainly factor analysis; other multivariate techniques displayed mostly descriptive effects. Histograms showed good results, discriminating populations mainly in terms of the "differentiation index" (ID) and the Niggli number qz.

The most important variation diagrams are the Streckeisen double triangles (QAPF) and the Niggli normative (QLM) since they compare modal and normative mineralogical data and evaluate sample and analytical errors eventually present.

ULBRICH, Mabel Norma Costas

Aspectos mineralógicos e petrológicos de nefelina sienitos do ma ciço alcalino de Poços de Caldas, MG-SP. 14 de fevereiro. 369p. Orientador: Celso de Barros Gomes

Resumo: Os nefelina sienitos do distrito alcalino de Poços de 
Caldas, MG-SP, afloram principalmente na parte setentrio nal e central do maciço, onde constituem corpos discré tos de colocação rasa. Mudanças na textura e mineralo gia das rochas, como também na estrutura dos corpos, pe $\underline{\underline{r}}$ mitem a distinção de vários tipos faciológicos.

Os minerais mais abundantes dessas rochas săo feldspato potássico e nefelina, acompanhados por quantidades va riáveis de piroxênio sódico, e às vezes, por biotita ou anfibólio arfvedsonítico. Os minerais acessórios variam nos diferentes corpos; em alguns acha-se presente uma mineralogia de rochas agpaíticas, com silicatos de me tais raros (principalmente eudialita), enquanto que ou tros são portadores de minerais típicos de rochas mias quíticas, tais como, titanita, biotita, opacos e fluor ta. A petrografia permite definir o caráter agpaitico ou miasquiticos das rochas, cujas evoluções diferentes explicam algumas particularidades químicas dos minerais, especialmente dos máficos.

o estudo detalhado do quimismo dos minerais mais impor tantes fornece elementos para interpretaçoes petrológi cas mais abrangentes. Os feidspatos potássicos são ge ralmente ricos em or e de estado estrutural variável nos diferentes fácies petrográficos. Na maioria dos casos coexistem microclínio de alta triclinicidade com esta dos menos ordenados nos mesmos cristais de feldspato, ou em diferentes cristais da mesma amostra. Esta feiçăo, somada à presença de microclínio máximo como único esta do estrutural em alguns fácies, sugere ordenamento estru tural submagmático controlado pela natureza peralcalina dos magmas e/ou soluções tardias. As nefelinas são "meio-potássicas"; nas rochas de granulação fina a mé dia apresentam teores elevados de excesso de silica, in dicando temperaturas de cristalizaçăo superiores a $700^{\circ} \mathrm{C}$ ou mesmo $800^{\circ} \mathrm{C}$ nas rochas miasquiticas e de aproximada mente $600^{\circ} \mathrm{C}$ nas agpaiticas. As nefelinas de rochas de granulação grossa concentram-se quimicamente no "campo de convergência de Morozewicz-Buerger", correspondente a temperaturas menores de $500^{\circ} \mathrm{C}$, sugerindo provável reequilíbrio submagmático. Os piroxênios variam de egiri na-augitas a egirinas. Em alguns fácies miasquíticos nota-se a presença de zoneamento contínuo de soda-augi tas $\rightarrow$ egirina-augitas $\rightarrow$ egirinas. As biotitas exibem va riações químicas marcantes, passando de ricas em $\mathrm{Mg}$ (biotitas iniciais) a portadoras de teores elevados de annita; na maioria dos casos são manganesíferas. 0 úni co anfibólio presente corresponde a uma magnésio arfved sonita manganesifera rica em $F$ e cuja temperatura mín ma de cristalização é estimada em 500-540 ${ }^{\circ} \mathrm{C}$.

No maciço alcalino distinguem-se vários fácies petrográ ficos, existindo, porém, poucos tipos de magma. Tenta tivamente, sugerem-se apenas dois, o miasquítico e o ag 
.70 .

paitico. Estes magmas invadem rochas supracrustais de cobertura (em parte piroclásticas) e tinguaitos cogené ticos, cristalizando-se a profundidade de poucos quilô metros, e provavelmente em câmaras fechadas. A ausência de enigmatita e faialita entre os minerais máficos das rochas menos agpaíticas indica que em geral os magmas cristalizaram sob condiçóes de $f_{02}$ superiores às do "buffer" FMQ.

ABSTRACT: Nepheline syenites in the Poços de Caldas alkaline district crop out mainly in the northern half of the massif as discrete bodies that were emplaced at shallow dephts. Several facies types can be identified in the field based on slight textural and mineralogical variations. The main rock-forming minerals are potash feldspar and nepheline, with variable but usually subordinate amounts of sodic pyroxene and, occasionally, biotite or anfvedsonite as well. Accessory minerals vary according to rock type: agpaitic nepheline syenites are characterized by rare-metal silicates(mainly eudialite), while miaskitic varieties exhibit sphene, fluorite, and ores. Some variations in mineral chemistry, especially in pyroxenes, are best explained as differences inherited from the miaskitic or agpaitic parent magmas.

Trends in magmatic evolution can best the followed by detailed studies of mineral chemistry. Potash feldspars in these rocks are usually or-rich, with variable structural states in the different petrogaphic facies. Highly ordered microcline coexists with less ordered feldspars, sometimes in the same grain, whereas in other facies only maximum microcline is found. These features suggest late magmatic or submagmatic re-equilibration, directly controlled by the peralkaline character of the magma or its residual solutions. Nephelines are of the "medio-potassic" variety; large amounts of excess silica are exhibited by nephelines in fine-grained nepheline syenites, indicating true magmatic crystallization temperatures of about $700^{\circ} \mathrm{C}$ to more than $800^{\circ} \mathrm{C}$ in miaskitic types and about $600^{\circ} \mathrm{C}$ in agpaitic types. Compositions of nephelines from coarser rocks cluster within the "Morozewicz-Buerger convergence field" evidencing temperatures of $500^{\circ} \mathrm{C}$ or less, thus suggesting subsolidus re-equilibration. Pyroxenes vary from aegirine-augites to aegirines. In some miaskitic facies, continuous zoning from soda augite to aegirine-augite to aegirine is observed. Biotites range from early Mg-rich varieties to late $\mathrm{Fe}-\mathrm{rich}$ types with substancial Mn contents. Mnrich Mg-arfvedsonite is the only amphibole found in some agpaitic rocks; a minimum estimate of crystallization temperature for this mineral is around $500-540^{\circ} \mathrm{C}$.

Although several lithological facies have been mapped, 
only two principal magma types are tentatively recognized herein, the miaskitic and the agpaitic types. Nepheline syenites, which are intrusive into genetically related vulcano-clastic rocks, now mainly eroded, and tinguaites, probably crystallized in closed magma chambers at depths of only a few $\mathrm{km}$. Lack of fayalite and aenigmatite in miaskitic varieties indicates that crystallization proceeded at $\mathrm{f}_{02}$ values higher than those of the FMQ buffer. 